DOCTRINA

\title{
La sentencia penal, el juez y el algoritmo: ¿Las nuevas tecnologías serán nuestros próximos jueces?
}

\author{
The criminal sentence, the judge and the algorithm: \\ Will new technologies be our new judges?
}

\author{
Juliana Vivar Vera \\ Tecnológico de Monterrey, México
}

\begin{abstract}
RESUMEN La sentencia penal implica en su construcción el raciocinio del juez penal acerca de hechos de violencia social clasificados como delitos y en ella el resultado condenatorio o absolutorio define la importancia de su precisión. Los softwares predictivos de sentencias están funcionando en los tribunales como asistentes de los jueces humanos y, en otras disciplinas jurídicas, como decisores autónomos. El presente artículo tiene por objeto analizar las consecuencias que tiene el funcionamiento de dichos softwares en el trabajo de los jueces encargados de dictar sentencias penales y, a partir de una reflexión crítica de elementos del derecho penal, la función judicial y el Estado, buscar una solución para los usos que se les pretende dar en ese contexto.
\end{abstract}

PALABRAS CLAVE Función judicial penal, software predictivo, justicia penal, decisión penal, algoritmo penal.

ABSTRACT The criminal sentence implies in its construction the reasoning of the criminal judge about acts of social violence classified as crimes and in which, the conviction or acquittal, defines the importance of its precision. Predictive sentencing software is operating in the courts, both as assistants to human judges and, in other legal disciplines, as autonomous decision-makers. The purpose of this article is to analyze the implications of the use and operation of predictive software in criminal sentencing and judges, based on a critical reflection of the theoretical elements of criminal law, the judicial function and the State, in order to find a solution regarding the intended uses of said software in judicial practice.

KEYWORDS Criminal judicial function, predictive software, criminal justice, criminal decision, criminal algorithm. 


\section{Introducción}

Si el significado de la sentencia penal fuera reducido a la decisión judicial condenatoria o absolutoria sobre la responsabilidad penal de una persona por la comisión de un delito, probablemente resolveríamos que la asistencia o incluso el reemplazo del humano por un procesador tecnológico sería de suma utilidad. Sin embargo, una sentencia penal tiene implicaciones de forma y fondo, tiene significado simbólico y trasfondo teórico jurídico, político, social y económico. Se trata de una construcción compleja que decide el futuro de las personas, la decisión última del proceso penal y ultimadora de un evento doloroso: decisión violenta para un acto violento. La participación de la tecnología en este evento, entonces, merece analizarse, criticarse y construirse.

El derecho penal, como rama del derecho, se va ajustando a los avances teóricos definidos por la epistemología que incide en el contexto jurídico de los Estados; en México, la reforma constitucional del 10 de junio de 2011 transformó el marco interpretativo para la adecuada adopción de los derechos humanos siguiendo la teoría alexyana como fundamento teórico, la cual guio la interpretación de los derechos fundamentales conforme al modelo de optimización de principios (Alexy, 1993). De ello se deriva que, en materia penal, la garantía de derechos humanos se encuentre legalmente presente en todo el proceso; sin embargo, el resultado punitivo justificado por la condena ha constituido una reconfiguración legal conforme a la teoría del derecho penal mínimo en su doble función preventiva: la de prevenir delitos y la de prevenir penas informales (Ferrajoli, 1995: 338 y ss.). La incertidumbre conceptual se refleja en la evolución normativa que surge a partir de la crítica epistemológica ${ }^{1}$ la contrapostura en materia penal, como es la concepción del derecho penal del enemigo de Günther Jakobs. ${ }^{2}$ Este ambiente teórico se combina con la llamada «exacta aplicación de la ley penal», que está presente en el derecho objetivo bajo la concepción de imputación de responsabilidad penal de acuerdo al «hecho que la ley señala como delito" y en cuya determinación la teoría dogmática del delito incide metodológicamente. De esta forma, la evolución epistémica, la contraposición de teorías y la aplicación normativa, complejiza la función del Estado en la regulación y aplicación punitiva a las violencias sociales, todavía más cuando se trata de sociedades en contexto de desigualdad.

Las ciencias exactas que dan luz a las combinaciones algorítmicas se introducen al sistema de justicia penal con la pretensión de ayudar a la actividad de sentenciar,

1. La teoría de Robert Alexy ha recibido críticas por autores como Juan Antonio García Amado, Manuel Atienza y Jan Sieckman, entre otros.

2. El enemigo en la concepción de Jakobs es aquel que se aparta voluntariamente del derecho y por ello el Estado no debe proporcionarle todas las protecciones legales en igualdad al ciudadano (Jakobs y Cancio Meliá, 2006). 
pero es necesario establecer de manera cuidadosa el tipo, momento y grado de intervención, puesto que sus postulados son distintos a los de las ciencias sociales. El derecho penal es la disciplina que se encarga de lo opuesto al bien común, es decir, de las conductas que fragmentan las relaciones humanas y que el Estado selecciona como delitos. En este sentido, la sentencia penal, ya sea absolutoria o condenatoria, es símbolo de justicia al abordar esas violencias con el objetivo de reparar y prevenir el daño, de modo de reducir las relaciones negativas entre las personas. ${ }^{3}$ Comprendido así, resulta necesario analizar si la decisión algorítmica con pretensión de exactitud es suficiente para esta tarea de impacto humano, donde las conductas varían y por tanto las modificaciones legales delictivas.

El avance tecnológico, en general, se relaciona con el sistema capitalista (Schirrmacher, 2014), puesto que la tecnología ha sido desarrollada principalmente por empresas privadas cuyos servicios son dirigidos en mayor medida a otras empresas o instituciones con objetivo de mercado; la oferta y demanda generan la innovación y para ello se ocupa la técnica humana. Los Estados más poderosos son los que gobiernan al mundo y han sabido trabajar con las empresas sobre la base de concesiones; dichas empresas, a partir de su capacidad económica, están diseñando y creando tecnología para hacerse cargo de las responsabilidades del Estado, incluyendo el control social de la violencia, en donde las desigualdades muestran a las personas vulnerables como las principales comisorias de delitos. En ese sentido, existe el riesgo de que el algoritmo se sesgue desde los datos de entrada, estableciendo solo algunos delitos y contra ciertas personas para el resultado final, es decir, la sentencia: el algoritmo contra la sociedad.

La normalización de los diversos usos tecnológicos ha sido bien recibida por las instituciones dado que auxilian a los servidores públicos a eficientar los procesos principalmente burocrático-técnicos. Las instituciones de justicia no fueron la excepción e introdujeron programas que se hicieran cargo de la «tramitología» para el efectivo acceso a la justicia y la transparencia del proceso penal de forma incipiente: en la publicación de resoluciones en línea, estado del expediente, etcétera; y en los juicios en línea y tecnología avanzada para las audiencias orales. ${ }^{4} \mathrm{La}$ experiencia exitosa de la evolución algorítmica del proyecto Watson de IBM, ${ }^{5}$ utilizado luego para

3. El Código Nacional de Procedimientos Penales, a partir de su artículo 402, define el contenido de la sentencia penal en cuanto a la convicción de juzgador, los requisitos generales y específicos en una sentencia absolutoria y condenatoria, así como la congruencia de la misma. Véase Código Nacional de Procedimientos Penales, Cámara de Diputados, 2014, disponible en https://bit.ly/3fbQcRd.

4. En 2008, México transformó su sistema de justicia penal a uno acusatorio y oral. La tecnología se implementó principalmente en las salas de oralidad y la justicia en línea. Con la pandemia se potencializó la justicia digital para juicios en línea.

5. Watson es una plataforma de inteligencia artificial para negocios que incluye machine learning, razonamiento y decisiones tecnológicas; así como lenguaje, habla y visión tecnológica capaz de interactuar 
el procesamiento de bibliografía en medicina y posteriormente en el ámbito jurídico, llevó a dar mayor oportunidad de adaptar la llamada «inteligencia artificial» (IA) ${ }^{6}$ al conocimiento legal para la razonabilidad predictiva en las sentencias.

La predicción de sentencias penales por los softwares representa una ayuda al juez y al Estado, sin embargo, este avance tecnológico ha sido implementado con cautela y solo en ciertos países debido a que la decisión judicial de condena o absolución es resultado de un proceso racional del contexto fáctico, legal y probatorio que impacta en la vida de los justiciables y, aunque «suele hablarse de "hecho" [...], en realidad, el dato que pone en marcha el proceso penal es más bien un resultado, que interpela al derecho, por sugerir como antecedente causal una acción humana que podría ser penalmente relevante» (Andrés, 2020: 113). Por ello es que aún algunos creadores de estas herramientas tecnológicas se ocupan de que permanezca la intervención humana (Estevez, Fillottrani y Linares, 2020). En otras materias ya se utilizan jueces robots (por ejemplo, en China en cuestiones de disputas digitales) que sentencian sin intervención humana y esta se hace presente hasta la revisión de la decisión judicial. Se prevé entonces que el avance y las técnicas de combinación algorítmicas (como lenguaje argumentativo jurídico, complejidad material y derechos humanos) que ya se están experimentando, incluso en el Tribunal Europeo de Derechos humanos y la Corte Interamericana de Derechos Humanos, hagan que el humano sea cada vez menos indispensable en la creación de sentencias penales.

Los jueces en el Estado constitucional de derecho tienen una gran responsabilidad en la función interpretativa del derecho, al caso concreto «Son más exactamente los garantes de la complejidad estructural del derecho en el Estado constitucional, es decir, los garantes de la necesaria y dúctil coexistencia entre ley, derechos y justicia» (Zagrebelsky, 1995: 153). A este respecto, la potenciación de principios debe caber en una interpretación directamente relacionada al caso sin implicar sesgos que desvirtúen tal responsabilidad. Sin embargo, se ha reconocido que la institución del Poder Judicial está implicada en contextos de corrupción ${ }^{7}$ que cuestionarían el rumbo de

con humanos para resolver problemas prácticos. Véase «¿Qué es IBM Watson y los sistemas de IA?», Inndot, 17 de junio de 2018, disponible en https://bit.ly/3n5do77.

6. Me referiré a este término en pocas ocasiones durante el desarrollo, porque es el que se utiliza en el lenguaje de las tecnologías, sin embargo, hago una crítica del mismo casi al final.

7. La Comisión Interamericana de Derechos Humanos (Véase «Corrupción y derechos humanos: Estándares interamericanos», CIDH, 2019, disponible en https://bit.ly/3ghNivc), destaca el rol de la administración de justicia donde al mismo tiempo de resultar afectado es agente de corrupción, por ello propone medidas, específicamente en materia penal, que no impliquen una violación a los derechos humanos y en general fortalezcan la independencia, imparcialidad, autonomía y capacidad en los sistemas de justicia. Así también el relator de la ONU, Diego García Sayán (véase «Corrupción, derechos humanos, independencia judicial», UNODC, 2018, disponible en https://bit.ly/3smkkwI), afirma que los sistemas judiciales están en la mira de la corrupción y del crimen organizado y esto reduce la confianza 
la sentencia, por lo que pareciera necesaria la participación del software predictivo como auxiliar o sustituto del juez humano. No obstante, es indispensable que sea la persona humana quien realice de inicio esta función decisoria considerando que sus características han estado aprisionadas por los límites legales que le impone su función, porque tiene relación con los seres a los que juzga y, aún sin saberlo, lo une con ellos más de lo que se ha podido percatar. Los límites impuestos por el Estado y la ley han mecanizado la labor judicial impidiéndole redescubrirse y valorarse para sentenciar con significado de responsabilidad al otro. Esta responsabilidad implica que aun en los casos que podrían representar poca complejidad para la formación del criterio judicial, lo cierto es:

Que, por su propia naturaleza, la prestación adecuada de la función demanda, no solo reflexión serena, sino también la interposición de alguna distancia cronológica entre el momento del enjuiciamiento y la formación y formalización de la decisión. Porque, generalmente, lo aprehendido por el juez en el acto del juicio es lo más parecido a un cuadro impresionista, de pinceladas poco precisas, en una suerte de apreciación de conjunto, que habría que desgranar analíticamente, decantar y perfilar. Pero es que, además, entiendo que el modo de hacerlo con las necesarias garantías de autoconsciencia y racionalidad debe pasar por someter el propio criterio a la prueba de la escritura (Andrés, 2020: 127-128).

Si el juez autoasumiera su dignidad y la de los justiciables, rompiendo la faceta de empleado funcional del Estado que cumple con un rutinario y mecanizado trabajo alienado por la ley y bajo la guía impuesta por el ente abstracto, transformaría su ser y el de las personas a las que juzga con una sentencia reflexiva y racional; el Estado, así, legitimaría su función social de control formal de la violencia sin necesidad de sucumbir ante la oferta de un producto que se ofrece mayormente funcional, más productivo, eficaz y eficiente en el dictado de sentencias penales.

Por eso es necesaria la reconfiguración del juez penal a partir de las características

\footnotetext{
pública y debilita la capacidad de los sistemas judiciales de garantizar la protección de los derechos humanos. Por ello es que 4.00o jueces de veinticuatro países colaboraron en la creación de la Red Mundial de Integridad Judicial (véase comunicado de la Organización de las Naciones Unidas contra la Droga y el delito, «Red mundial de integridad judicial», disponible en https://bit.ly/3vo4460) para ayudar a la judicatura del todo el mundo a reforzar la integridad judicial y prevenir la corrupción en el sector de justicia. Por otro lado, a manera de ejemplificar, en México, en la Reforma Judicial con y para el Poder Judicial (Suprema Corte de Justicia de la Nación, 202ob) se reconoce que la corrupción no se ha podido desterrar y propone reglas para evitar subjetividades y favoritismos. Asimismo, en un estudio enfocado en México, Perú y Colombia (véase Carvajal, Hernández y Rodríguez, 2019: 81) se determina que existe cierta aceptación frente a los actos de corrupción judicial y las causas identificadas son los bajos sueldos, la inoperancia del sistema judicial, la aceptación social de la corrupción y la intervención de los grupos de poder en los sistemas judiciales.
} 
que lo definen y diferencian de la máquina; de este modo la sentencia penal tendrá un sentido, esencia y rumbo distinto para la persona que juzga y a las que juzga.

El presente artículo pretende realizar un análisis crítico de la función creadora de la sentencia penal y su relación con la tecnología, principalmente la incidencia de los softwares predictivos en el contenido y finalidad de la misma; así también, tiene como objetivo analizar la función de los jueces penales humanos y su relación con estos sistemas tecnológicos, previendo su desplazamiento en la elaboración de sentencias penales.

Para lograr esta pretensión en el primer apartado se analiza el rol del algoritmo matemático en la construcción de la sentencia penal para detectar el alcance de sofisticación en la completa y correcta traducción algorítmica de la realidad de la ley, la teoría y las personas. En el segundo apartado se analiza la participación de la persona que realiza la actividad de sentenciar penalmente, destacando semejanzas y diferencias con el software predictivo. Por último, se destaca la importancia de la sentencia penal en el derecho penal y la teoría del derecho en relación con los elementos fácticos interseccionales a considerar y se proponen los inicios de una reconfiguración de la función judicial y su relación con la tecnología con énfasis en la evaluación de la tangibilidad de la propuesta.

\section{El algoritmo matemático en la construcción de la sentencia penal}

Como una opción de mejoramiento de la justicia, la cibernética se asoma al seductor trabajo de toma de decisiones judiciales. ${ }^{8}$ El software predictivo de la decisión acorde al caso funciona con algoritmos de selección de datos de la red que permiten filtrar los necesarios y aplicables al caso. El avance es tal que el aprendizaje profundo y el aprendizaje automático, ${ }^{9}$ como ramas de la llamada «inteligencia artificial», representan el aprendizaje complejo visto como oportunidad de ayuda o sustitución del juez humano para una decisión correcta y justa.

La tecnificación de la tecnología ha basado su esfuerzo en prueba y error con el objetivo del perfeccionamiento libre de sesgos subjetivos (Sourdin, 2018). Si esto es así, ¿por qué los países tienen reservas para su implementación?

El llamado «sesgo algorítmico» es comparable con el «error judicial» identificable en el encabezado de la sentencia, en los fundamentos de hecho, en los fundamen-

8. La decisión judicial está apoyada por algoritmos en ciertas partes del mundo, por ejemplo, el algoritmo Prometea ha registrado su trabajo en la Corte Interamericana de Derechos Humanos, en Argentina y Colombia (Estevez y otros, 2020: 67). También en el Tribunal Europeo de Derechos Humanos respecto a la violación de derechos humanos (Aletras y otros, 2016). En Estados Unidos, con resultados polémicos en ciertos casos como lo fue el de State vs. Loomis (Brennan, Dieterich y Ehret, 2008).

9. En inglés Machine learning y deep learning. Ver Keith Darlington, « ¿Pueden las tecnologías actuales emular la inteligencia humana?», Open Mind BBVA, 2 de diciembre de 2019, disponible en https:// bit.ly/347eqFx. 
tos de derecho y en el fallo (Malem, Ezquiaga y Andrés, 2012: 16). Por supuesto que el ejemplo del procesador COMPAS (Correctional Offender Management Profiling for Alternative Sanctions) queda en esta discusión por lo evidenciado que fue en la acusación acerca de supuestos sesgos raciales y de género que contenía y generaba una calificación de riesgo correspondiente a la pena que debía imponerse. Así fue planteado el 23 de mayo de 2016 por ProPublica, organización sin fines de lucro, en el artículo «Machine Bias», ${ }^{10}$ donde advierte sobre el sesgo racial del software, tomando como referencia algunos casos, principalmente el de Brisha Borden y Vernon Prater; sin embargo, no fueron los únicos, ya que en julio de ese año se dictaba una sentencia de apelación por una decisión judicial que imponía una pena incorrecta por recomendación del algoritmo. ${ }^{11}$ En contextos regionales determinados, los sesgos pueden implicar un tipo de discriminación específica (raza, color, sexo, religión, idioma u origen social) que contraviene el principio de igualdad ante la ley y ello está prohibido si tiene por objeto anular o menoscabar los derechos y libertades de las personas para lo cual, en caso de error judicial, procede la reparación del daño de acuerdo a los artículos 17, 24 y 27 de la Convención Americana de los Derechos Humanos.

Por supuesto que la empresa Northpointe Suite, de la cual depende el sistema informático COMPAS, respondió a estas acusaciones centrándose en la validez científica del software, que solo podría ser interpretado con conocimiento sólido de las técnicas y matices metodológicos comunes hacia la materia. ${ }^{12}$ Lo cual da lugar a la necesidad de una especialización del funcionamiento técnico del software para comprender las combinaciones algorítmicas que deberían encontrarse reguladas para la comprensión del proceso de determinación de la acreditación de la responsabilidad penal.

Para su justificación, la misma empresa presentó datos técnicos que contiene el procesador: la Escala General de Riesgo de Reincidencia (GRRS, por sus siglas en inglés), que incluye la escala de participación criminal, la subescala de problemas de drogas, edad en el momento de la evaluación, edad en la primera adjudicación, número de arrestos previos, tasa de arrestos y la escala de educación vocacional; y la Escala de Riesgo de Reincidencia Violenta (VRRS, por sus siglas en inglés), edad en el momento de la evaluación, edad en la primera adjudicación y la escala de historia de la violencia. Las escalas de riesgo se dividen en niveles bajo, medio y alto y los tipos

10. Véase Julia Angwin, Jeff Larson, Surya Mattu y Lauren Kirchner, «Machine Bias», ProPublica, 23 de mayo de 2016, disponible en https://bit.ly/3pUoLPX.

11. Supreme Court of Wisconsin, «STATE of Wisconsin, Plaintiff-Respondent, v. Eric L. LOOMIS, Defendant-Appellant», alegada el 5 de abril de 2016, fallada el 13 de julio de 2016, disponible en https:// bit.ly/zziDHvb.

12. Véase Equivant, "Official Response to Science Advances», 18 de enero de 2018, disponible en https://bit.ly/3cEmNwh. 
principales de estadísticas de clasificación son «errores del modelo» y «errores de la población objetivo». Estos datos de cálculo técnico dan pauta a que el rango de pena de los tipos penales sea individualizado en una pena exacta, sin embargo, estos datos que tienen como fin un cálculo matemático, si bien son parecidos, se distinguen por reducir la discrecionalidad judicial a fin de que el juez cuente con elementos que encuadren su motivación y fundamentación en la decisión penal.

La empresa aceptó el error en el procesador, aunque no el sesgo discriminatorio, pues afirmó que estos fueron resultados de porcentajes de entrada en la población objetivo. Los acusados afroamericanos que fueron predichos a la reincidencia, realmente reincidieron en una tasa más alta (63\%) que las personas blancas (59\%). El análisis de Northpointe encontró que las personas blancas que reincidieron dentro de los siguientes dos años fueron clasificadas erróneamente como bajo riesgo casi dos veces, tan a menudo como los reincidentes afroamericanos ( $48 \%$ y $28 \%$, respectivamente). Así mismo, los acusados blancos que se predijo que no reincidirían, en realidad no reincidieron a una tasa más alta $(71 \%)$ que las personas afroamericanas $(65 \%)$. Esto proporciona evidencia de paridad predictiva para el GRRS para afroamericanos y personas blancas en la población objetivo (Dieterich, Mendoza y Brennan, 2016).

La empresa no dio detalles de la metodología de combinación de datos bajo el argumento de la protección del secreto empresarial, pero probablemente la causa fue que el seguimiento de lo procesado quedó fuera del control humano por el aprendizaje automático, lo comúnmente llamado «cajas negras».

Con esta evidencia del funcionamiento del procesador, podemos afirmar que:

- La simple sospecha de sesgo algorítmico discriminatorio crea un clima de desconfianza de la justicia y de la decisión penal. Para revertir esta apreciación el estándar de duda razonable conllevaría la absolución por la aplicación del principio de presunción de inocencia por la falta de convicción o certeza de la existencia del hecho delictivo y de la responsabilidad penal del acusado producto de la valoración del caudal de pruebas practicadas en juicio oral, es decir que no se logró acreditar completamente la responsabilidad penal (Suárez, 2011: 324) que la teoría del delito sistematiza dogmáticamente en elementos positivos y negativos para tal ejercicio.

- El profesor Caterini ${ }^{13}$ analiza la valoración algorítmica en la duda razonable y propone partir de la interpretación in dubio pro reo que los sistemas expertos deberían implementar basados en precedentes de hecho que ofrezcan opciones interpretativas que elijan el más favorable al acusado y no el estadísticamente más frecuente. Con esto, si se trata de auxiliar al juez en la decisión

13. Mario Caterini, «Il giudice penale robot», p. 19 y ss., La legislazione Penale, 19 de diciembre de 2020, disponible en https://bit.ly/3gk49gU. 
penal sería en sentido absolutorio o más leve, lo que podría refutarse por el juez con una carga motivacional más rigurosa capaz de destruir el argumento del sistema experto. Parecería factible la propuesta del profesor porque la afectación de derechos en la condena debe partir de datos de entrada exactos y suficientes para la debida justificación; además, para la individualización de la pena incluso valdría tomar en cuenta la incidencia de la víctima (Montano, 2016) y no solamente la de la persona a quien se adjudica la responsabilidad penal. A diferencia de lo que se observa en el caso previamente citado, en el que los datos de entrada para el etiquetamiento de nivel de riesgo imputado a una persona parecieran corresponder al "peligrosómetro» positivista, término coloquial con el que se refería al sistema científico de "prognosis estadística» para medir la peligrosidad — que inició siendo intuitiva y luego se tecnificó- y que consiste en estudiar un grupo más o menos numeroso de reincidentes y cuantificar "causas» de reincidencia. Con base en la información así levantada se construye una tabla, se suman las causas presentes y ausentes en cada caso futuro y se obtiene el porcentaje, o bien se asigna un número de puntos a cada «causa» y se suman los puntos, aunque hubo algunos más complicados. Estas tablas se desarrollaron por algunos autores en Alemania y en los Estados Unidos, pero no prosperaron porque de inicio no supieron captar bien el estereotipo y, además, no podían tener en cuenta el resultado deteriorante y condicionante del proceso y de la institucionalización (Zaffaroni, 1998: 244) que implica una regresión y se contrapone con el estado actual de la teoría del derecho y del derecho penal explicada al inicio de este apartado, un derecho penal de autor y no de acto clasificado para el estudio clínico;

- El conocimiento científico sólido del lenguaje de programación limita y se contrapone a un derecho por y para la sociedad, entendible, entendido y reconocido. Aun como auxiliar, el conocimiento del juez respecto a su asistente es limitado, lo cual cuestiona el binomio perfecto judicial humano-máquina;

- El error del algoritmo no reduce el error judicial y aunque es ajeno al humano sigue siendo éste responsabilizado, como ocurrió en el caso State v. Loomis (Supreme Court of Wisconsin, 2016). A pesar de que los tribunales tienen la obligación de evaluar la decisión algorítmica y estar o no de acuerdo con ella, la obtención de los datos de entrada debería partir de un sistema penal efectivo que es clave en el Estado de derecho, sin embargo, las cifras muestran en la mayoría de los países lo contrario (World Justice Project, 2020: 29). Asimismo, existe la duda de que toda la ley existente se encuentre en la máquina y más que sea traducida en código algorítmico con la misma sintaxis y semántica y pueda actualizarse conforme a las reformas legales y al entorno cambiante, debido a que los programadores rara vez tienen experiencia legal ni son ex- 
pertos en políticas o administrativos (Sourdin, 2018: 1127). y es posible que den un contexto incompleto o distinto al que deben tomar en cuenta los jueces para resolver El algoritmo matemático depende de los datos de entrada para hacer combinaciones y arrojar una predicción exacta, pero estaría cuestionada su justicia en tal precisión, puesto que tales datos de entrada probablemente sean insuficientes para una predicción que contemple el enfoque material, es decir, el contenido de verdad y de corrección de las premisas, de tal manera que el paso de estas a la conclusión sea lógica y deductivamente válido, en otras palabras: que se logre la justificación interna (Atienza, 1994). Lo anterior a diferencia de una predicción algorítmica que contenga al menos una premisa con duda de sesgo y por tanto que arroje resultados erróneos, como en el ejemplo del cuestionario aplicado al sospechoso en el caso State v. Loomis ${ }^{14} \sin$ embargo, en un proceso de aprendizaje automático del algoritmo resulta difícil identificar el elemento detonante del error en la predicción y se corre el riesgo de continuar su funcionamiento con la permanencia de tal sesgo e irse alimentando con los casos posteriores que resuelva dictados en el mismo sentido y;

- La transparencia que los sistemas penales intentan hacer valer se ve mermada por los sistemas de cajas negras donde se advierte la pérdida de control de la técnica de procesamiento. Esto pone en duda el resultado de exactitud, toda vez que el momento de penumbra en el seguimiento paso a paso impide dar certeza de la fortaleza del resultado y, por tanto, la motivación de la predicción, que debería contener argumentaciones para la justificación interna y externa sobre la valoración probatoria, no podría considerar en la externa los problemas de relevancia, interpretación, prueba y calificación que constituyen los problemas del caso y que como tal están llamados a ser guía metodológica para la praxis jurisdiccional (Zavaleta, 2014: 149).

Por tanto, el juez humano y la máquina incurren en error, son selectivos y estigmatizantes, en gran medida como resultado de que los datos ingresados a la máquina y los observados por el juez humano son tomados de una realidad parcial, desigual y vulnerada, y de una la ley que limita la descripción de conductas delictivas a las más graves bajo el principio de fragmentariedad que se contrapone con la totalidad de las ocurridas en la realidad y que problematizaría los datos del contexto social completo de violencia. Ni el juez humano ni el software son capaces de comprender la realidad total de la ley; por un lado, el juez humano decide con base en lo que las partes le muestran en juicio, por otro, la máquina depende de una realidad construida y preseleccionada por programadores lejanos a los conceptos sociales.

14. Cuestionario disponible en Julia Angwin, «Sample-COMPAS-Risk-Assessment-COMPAS"CORE"», disponible en https://bit.ly/2GcO6Sd. 
Para evitar el error, el enfoque de interpretación para la garantía de derechos humanos debe ser sobre la completitud de la realidad y la ley, pero esto aún sigue siendo un reto vigente. Si el juez tiene una realidad distinta y parcial, no solo no hará una correcta interpretación legal, sino que la afectación legítima de los derechos humanos se tornaría en una violentación de los mismos por una incorrecta valoración de los hechos, en relación con la prueba y la ley. Todo esto en el contexto de que la preponderancia del hecho y su valoración son el eje para la optimización de principios en un Estado constitucional principialista; en contradicción, la ley penal otorga parámetros para la imposición de sanciones que limitan este actuar.

El software predictivo parte de la lectura de resoluciones previas puestas en línea, en su paneo solo ocupa palabras clave precargadas para hacer la búsqueda con el número de expediente y, de acuerdo con el caso, afina con algunas preguntas al usuario la solución que dará en segundos. Acto seguido, muestra en pantalla al usuario o relator el modelo que debería utilizar (Corvalán, 2018). Puede observarse que la intervención humana es mínima y la intención de los programadores es que llegue a ser innecesaria (Sourdin, 2018: 1122 y ss.). Con este objetivo de perfeccionamiento de las combinaciones algorítmicas continúa el avance del aprendizaje profundo (deep learning) (Chollet, 2018: 8), subcampo específico del aprendizaje automático que consiste en un aprendizaje de capas sucesivas cada vez con más representaciones significativas, de tal manera que implique menos participación de ingenieros humanos gracias a la aplicación de técnicas como la retropropagación (backpropagation) ${ }^{15}$ que apuntan al desarrollo de la capacidad de razonamiento formal; algo parecido a AlphaGo, ${ }^{16}$ que se desarrolla automáticamente en lugar de ser codificado por humanos. Mientras tanto, el aprendizaje profundo sigue siendo utilizado para reducir la carga cognitiva técnica, como lo ofrece el desarrollador Keras. ${ }^{17}$

15. Es el algoritmo maestro utilizado para entrenar redes neuronales profundas, funciona para propagar una señal de retroalimentación desde la pérdida de salida hacia las capas anteriores. Si esta señal de retroalimentación tiene que propagarse a través de una pila profunda de capas, la señal puede volverse tenue o incluso perderse por completo, haciendo que la red sea imposible de entrenar. Se conoce como gradientes que desaparecen. Véase Chollet, (2018: 246).

16. Es un programa informático de inteligencia artificial desarrollado por Google DeepMind para jugar al juego de mesa Go. Es el primer programa de computadora en derrotar a un jugador de Go humano profesional. Combina un árbol de búsqueda avanzada con redes neuronales profundas. Estas redes neuronales toman una descripción de la placa Go como entrada y la procesan a través de varias capas de red diferentes que contienen millones de conexiones tipo neurona. Una red neuronal, la «red de políticas», selecciona el próximo movimiento para jugar. La otra red neuronal, la «red de valor», predice el ganador del juego. Para mejorar, lo hicieron jugar contra diferentes versiones de sí mismo miles de veces, aprendiendo cada vez de sus errores. Con el tiempo, AlphaGo mejoró y se volvió cada vez más fuerte y mejor en el aprendizaje y la toma de decisiones. Veáse «AlphaGo», DeepMind, disponible en https://bit.ly/3zEIsQ7.

17. Puede consultarse más sobre ello en https://keras.io/. 
La intención de sustituir al humano por un robot en la labor predictiva penal se lograría a partir de cambiar las técnicas de aprendizaje profundo, que actualmente solo mapean insumos de formación a los objetivos de entrenamiento punto por punto; por eso es que el desarrollo actual de la investigación implica tanto razonamiento y abstracción a partir de la intuición para lograr una argumentación lógica, así como minería y análisis de textos legales, donde se toman modelos de razonamiento y representación del conocimiento legal conforme a la teoría jurídica, la interpretación legal y la incidencia de la dimensión epistémica de la política. Los modelos de razonamiento avanzados que se están desarrollando en este sentido son el A-BOX (assertions on individuals), el T-BOX (assertions on concepts), y el GSC (gold standard corpora) para el análisis sintético y semántico, además de estar proponiendo crear un corpus de normas multilingües. ${ }^{18}$ Esta combinación de datos con espectro amplio de contexto en sus diferentes variables podría suponer la exactitud del algoritmo en la predicción de la sentencia al mismo tiempo de acercarse a la justicia, puesto que la interpretación extensiva acorde a las reglas de subsunción de reglas y potenciación de principios sería reconocida como motivación en el argumento de la sentencia penal a la vez que en la individualización de sanciones y reparación del daño a la víctima. No solo eso, puesto que también sería útil en momentos procesales penales previos al juicio oral, como la etapa intermedia para la aplicación de la regla de exclusión probatoria por ilicitud, que coincide con un debido proceso como derecho humano y que se refleja con la fuerza de una garantía intrínseca de carácter constitucional (Anaya y Anaya, 2016: 29) con objeto de obtener la verdad de los hechos y evitar la impunidad por defecto de la prueba (Fonseca, 2016: 52); o también al momento de la imputación o acusación en audiencia. Todos ellos son filtros indispensables para que los elementos de prueba a desahogar en el juicio oral sean suficientes y legales para ser sujetos a valoración judicial.

Por eso las intersecciones valorativas de la justicia diferenciada son esenciales para la interpretación material y no violatoria de derechos humanos en la efectiva aplicación de la justicia — como es la perspectiva de género, justicia para adolescentes, justicia restaurativa, usos y costumbres en comunidades indígenas, entre otras-, ya que permiten relacionar el caso con modelos teóricos o epistémicos de los que deriva la función del derecho, como el decolonialismo y las teorías de violencia y de paz, teorías feministas, etcétera. Es una realidad que tampoco el juez atiende la totalidad de este complejo bagaje y que el auxiliar tecnológico pudiera asistirle en mostrar estos datos; sin embargo, la traducción de las desigualdades particulares deviene de fenómenos amplios para incidir en contextos sociales problemáticos.

Pongamos como ejemplo el caso González y otras vs. México, también llamado

18. Puede encontrarse mayor referencia y detalle de los proyectos en https://www.mirelproject.eu/ y en http://lidia.cs.uns.edu.ar/home/. 
«campo algodonero», a efecto de interpretar el contexto en el que se producen asesinatos con ese particular ensañamiento debe apuntarse a las causas de dicho resultado; así lo resolvió la Corte Interamericana de Derechos Humanos en 2009, al decir que las víctimas fueron violadas y abusadas con extrema crueldad y, por tanto, debía considerar parámetros para determinar, prevenir, investigar, procesar y castigar la violencia de género en general dentro del Estado mexicano, es decir, estableció directrices para identificar cuando estamos frente a casos cuyo móvil es la violencia de género (CIDH, 2009). La complejidad del elemento subjetivo «género» en la descripción típica del feminicidio no solo trata de un encuadramiento al hecho, sino que también requiere que sea comprobado a partir de elementos de construcción cultural regionalizados; parecería entonces que sólo el juez humano podría tener el nivel de comprensión necesario para esta tarea al formar parte de esa realidad social. Además, en este ejemplo, si se trata de un caso nuevo puede ser que el software no tenga elementos para predecir por no tener precedentes con los cuales relacionarlo o, si los hay y son suficientes, que se hayan resuelto con una debida interpretación de la perspectiva de género tomando los elementos anteriores que den sentido a la ley que aplicó, de lo contrario, la máquina tomará el sesgo de falta de perspectiva de género y lo perpetuará.

Otra cuestión en el impacto de la intervención algorítmica en la decisión penal es la reparación del daño a la víctima, la cual comprende la devolución de los bienes o el pago por los daños o pérdidas sufridos, el reembolso de los gastos realizados como consecuencia de la victimización, la prestación de servicios y la restitución de derechos. ${ }^{19}$ Sin embargo, la reparación del daño tiene un significado más profundo que también implica discrecionalidad judicial: a pesar de los datos que se muestren al juez, este debe hacer una correspondencia entre el impacto del daño por el delito y lo que esté en posibilidad de cubrir el sujeto activo. Los modelos de reparación del daño incluso contemplan la llamada reparación integral, como es el caso de México y el de Colombia ${ }^{20}$ que representan una reparación «oportuna, plena, diferenciada, transformadora, integral y efectiva por el daño que han sufrido como consecuencia del delito o hecho victimizante que las ha afectado o de las violaciones a derechos humanos que han sufrido, y comprende medidas de restitución, rehabilitación, compensación, satisfacción y de no repetición» (CEAV, 2015: 34). El juez escucha la propuesta del asesor jurídico de la víctima y luego al activo para tomar una decisión acorde a las

19. Véase «Declaración sobre los principios fundamentales de justicia para las víctimas de delitos y del abuso de poder», resolución 40/34 de la Asamblea General de las Naciones Unidas, 29 de noviembre de 1985, disponible en https://bit.ly/3xHD7Wy.

20. Véase Congreso de la República (2011). Por la cual se dictan medidas de atención, asistencia y reparación integral a las víctimas del conflicto armado interno y se dictan otras disposiciones. Disponible en https://bit.ly/3giOluR. 
medidas de ley, los argumentos de las partes y las pruebas presentadas. Estos elementos, en lo formal, podrían ser contemplados por el software, sin embargo, lo material que resulta del enfoque diferenciado para el caso concreto sin duda requiere de la sensibilidad humana, por eso los procesadores predictivos como Prometea, Xiao Fa y Northpointe suite risk need assessments, entre otros, aún reservan la decisión a revisión última por los jueces humanos.

Los países y las asambleas internacionales en el mundo, principalmente en Europa y Latinoamérica, se están pronunciando para un avance tecnológico de la inteligencia artificial con ética y respeto a los derechos humanos para mantener la confianza gubernamental, la integridad, privacidad, responsabilidad y uso confiable, a fin de que el desarrollo tecnológico no solo sea técnico. La Asamblea Parlamentaria de Europa considera que es necesario crear un marco normativo transversal para la IA, con principios específicos basados en la protección de los derechos humanos, la democracia y el estado de derecho (Parliamentary Assembly, 2020). En la resolución $2342^{21}$ identificó que algunas formas en el uso de la inteligencia artificial en el sistema de justicia penal son incompatibles con los principios éticos, tales como: denegar el código fuente y adquirir la propiedad de los datos procesados por empresas privadas, contaminación de sesgos de los datos masivos, dependencia a estos sistemas y reducción de toma de decisiones plenamente informadas, consecuencias graves imprevistas o involuntarias en la adición de elementos de IA. Por ello la Asamblea recomienda: adoptar un marco ético legal nacional para regular el uso de IA, mantener un registro público de todas las aplicaciones de IA y consultarlo para considerar nuevas aplicaciones, garantizar que la IA sirva a los objetivos de las políticas y que los objetivos de las políticas no se limiten a las áreas de la IA, garantizar que exista una base legal suficiente para cada solicitud de IA y para el procesamiento de datos relevantes, garantizar que todos los organismos públicos que implementan aplicaciones de IA tengan experiencia interna capaz de evaluar y asesorar sobre la introducción, operación e impacto de tales sistemas, consultar de manera significativa a la ciudadanía antes de introducir aplicaciones de IA, asegurar que cada nueva aplicación de IA esté justificada en propósito y efectividad, realizar evaluaciones iniciales, periódicas y transparentes del impacto sobre los derechos humanos de las aplicaciones de IA en privacidad y protección de datos, riesgos de sesgo o discriminación y consecuencias para las personas, principalmente en minorías y grupos vulnerables y desfavorecidos, asegurar que los procesos de IA de toma de decisiones sean explicables a sus usuarios, establecer mecanismos de supervisión ética y judicial efectivos e independientes para la introducción y operación de los sistemas de IA.

Tomando datos del Tribunal Europeo de Derechos Humanos, en estudios expe-

21. Resolución del 22 de octubre de 2020, «Justice by algorithm - The role of artificial intelligence in policing and criminal justice systems» Parliamentary Assembly, disponible en https://bit.ly/3vazyX2. 
rimentales (Medvedeva, Vols y Wieling, 2020) de uso de las herramientas de procesamiento del lenguaje natural para analizar textos de procedimientos judiciales para predecir automáticamente (futuras) decisiones judiciales, se detectó un $75 \%$ de precisión en la predicción de infracciones de nueve artículos del Convenio Europeo de Derechos Humanos, lo cual destaca el potencial de los enfoques de aprendizaje automático en el ámbito legal, sin embargo, el predecir decisiones para casos futuros basados en los casos del pasado impacta negativamente en el rendimiento (rango de precisión promedio de 58 a $68 \%$ ).

Por otro lado, la ONU (Organización de las Naciones Unidas) propugna por el llamado «bienestar digital» y cumplimiento de los diecisiete Objetivos de Desarrollo Sostenible (ODS) de las Naciones Unidas y advierte la desatención de la IA en la desigualdad social, teniendo como único objetivo el mercado, cuestión que, de seguir así, reproducirá y exacerbará los sesgos. También advierte que la IA es diseñada y creada por hombres blancos, con recursos y procedentes del norte global que reflejan sus propias perspectivas aun cuando estén comprometidos con los valores humanos. El modo de contrarrestar estos sesgos es garantizando los derechos humanos desde las prácticas en las que se basa la creación, la auditoria y el mantenimiento de los datos bajo un escrutinio muy intenso (Asamblea General de las Naciones Unidas, 2019). Es por ello que los desarrolladores de softwares actualmente están haciendo esfuerzos para adaptarlos al enfoque teórico complejo de aplicación de justicia respetuosa de derechos humanos acorde al Estado constitucional, de forma que los términos «dignidad», «libertad» $y$ «transparencia» sean valores que tendrán una medición en los algoritmos. Juan Corvalán (2018) afirma que para que la IA sea compatible con un «modelo de derechos humanos» es necesario incorporar principios al marco jurídico: prevención/precaución, autodeterminación algorítmica, transparencia algorítmica y principio de imparcialidad del validador, trazabilidad de la inteligencia artificial, máximo acceso a la información algorítmica y principio de no discriminación algorítmica. Todos estos principios están vinculados con tres categorías: dignidad algorítmica, identidad algorítmica y vulnerabilidad algorítmica (Corvalán, 2018: 310-313), lo cual implica un rediseño en las relaciones de los sectores público, privado y social que contemple las nuevas relaciones entre humanos y máquinas para desarrollar algoritmos de verificación independientes que puedan cuantificar y certificar de alguna manera esta capacidad de intuición, inteligibilidad, adaptabilidad y adecuación de los objetivos del robot. ${ }^{22}$

Al menos es un avance la discusión de la garantía de derechos humanos en la intervención algorítmica; sin embargo, y tomando en cuenta que la dignidad humana es la fuente de los derechos humanos pero no pertenece al campo del derecho ni al

22. Paolo Benanti, «La dignidad de la persona en la era de Máquina Sapiens», Fundación Fide, disponible en https://bit.ly/3hOnqrS. 
de ninguna otra ciencia, las reflexiones sobre autonomía de la voluntad son y serán permanentes, así como también estarán presentes las desigualdades sociales, solo que estas tienen posibilidad de ser reducidas, a diferencia de los derechos humanos y la dignidad de las personas, que actualmente se potencian y garantizan por el Estado y no por las empresas. La dicha garantía se propugna porque el Estado debe tener la responsabilidad de regular, controlar y supervisar el uso del sistema experto de IA cuando se dirija a las personas de modo de asegurar que sea una herramienta al servicio del ejercicio de los derechos humanos.

Se espera que las empresas desarrolladoras de softwares redirijan su objetivo de mercado al bienestar social y a la reducción de desigualdades, y en el ámbito de la decisión judicial penal, que intervengan en garantizar que la misma no contravenga derechos humanos. Sin embargo, se puede apreciar que el avance acelerado de la tecnología ha traspasado el control regulatorio estatal privilegiando el "poder hacer» antes del «deber hacer», y por ello se llama a que sean las propias empresas las que involucren la ética en sus procesos de diseño, creación e implementación de softwares. Este debería ser un primer paso verificable antes de que los Estados introduzcan esta tecnología en sus servicios públicos, previendo su uso para el desarrollo social igualitario y la justicia para que los contratos de softwares tengan ese propósito alcanzable.

Es importante que las empresas consideren, además, el limitado panorama que contempla la ley en relación a los hechos sociales al momento del trabajo predictivo de la decisión penal y que los valores que las combinaciones algorítmicas más sofisticadas pueden alcanzar se logran a partir de normas y principios positivizados en el orden jurídico nacional e internacional, pero no podrían interpretar aquellos hechos que no son identificados jurídicamente como delitos por el principio de fragmentariedad o por la interpretación de multiplicidad de cosmovisiones, como las de los pueblos indígenas, donde los usos y costumbres no son expresos y que en la actualidad son parte de la compleja incertidumbre de justicia. Así, la pretensión de una «dignidad algorítmica» ${ }^{23}$ para una declaración estatal de protección y garantía de los derechos humanos en una decisión judicial penal es errónea desde la pretensión del postulado de cosificar a datos el contexto situacional de las personas en sociedad, en comunidad, en lo individual y en sus interrelaciones, a través de leyes en constante cambio que tampoco contemplan la totalidad de conductas sociales y que en ocasiones se muestran incompletas en el dictado de la sentencia penal.

23. Es una de las categorías que propone Corvalán (2018) para vincular principios de protección a los derechos humanos de las personas en un ambiente de datos que pueden poner en riesgo su autodeterminación de la información. 


\section{El juez penal y el algoritmo. Control y elegibilidad}

No es posible suponer una sentencia penal de forma y fondo sin que algo o alguien la haya dictado; es indudable que la relación entre el contenido y su sentido tienen coincidencias con la mano humana y el algoritmo digital, o que a su vez que existan coincidencias y divergencias entre la persona y la máquina y, luego, entre estas y la sociedad.

El algoritmo predictivo no fue diseñado para dictar sentencias penales $y$, por otro lado, la tecnología fue diseñada y construida a partir de las posibilidades científicas infinitas de las personas expertas en las ciencias exactas. Los múltiples usos de la tecnología son los que derivaron en la opción de ayudar a las personas a facilitar su cotidianeidad y, por ello, las tareas técnicas son las que van siendo delegadas cada vez más a las máquinas.

Asimismo, el ser humano no fue creado para dictar sentencias penales. Aún la humanidad se esfuerza por dar explicación al origen de la vida más allá de la que otorga la medicina sobre su nacimiento y sobre su ilimitada capacidad técnica para destruir y construir, puesto que el objetivo de su vida no fue cumplir una sola función ni que su existencia compitiera con una creación propia. El diseño humano en su conjunto - mente, cuerpo y alma - es perfecto per se, al grado de ser inexplicable en su totalidad, y sería ocioso hacerlo porque los esfuerzos de la multiplicidad de tareas que realiza son a partir de los cuales se comprende, al igual que los motivos de sus acciones.

Por eso es que la función de sentenciar es solo una de tantas que se les ha asignado a ciertas personas dentro de las facultades previstas por el ius puniendi que, por otro lado, también se le ha otorgado a una creación humana, ya sea como equipo o de forma independiente, derivada a su vez de su capacidad para diseñar y ejecutar, aunque el que se interpone entre estos verbos: el crear, solo el humano lo pueda hacer.

Dichos avistamientos de coincidencia y diferencia, trasladados a la acción de sentenciar conductas humanas seleccionadas como delitos por el Estado, han dado lugar a que esta facultad legal sea adjudicada a las personas y no a las máquinas. Este hacer representa una gran responsabilidad directamente con otra persona e indirectamente con el Estado y la sociedad. Los diversos sentidos e impactos - principalmente aquellos negativos- de las sentencias penales son atribuidos a cuestiones derivadas de la subjetividad humana, como son la preconcepción, la corrupción, la falta de capacitación y el exceso de trabajo, y debido a ello se considera la pertinencia de apoyarse en la capacidad predictiva de la IA, que se presenta con características de objetividad, neutralidad e infalibilidad. El «juez Hércules» humano del que hablaba Dworkin parecería que finalmente se convierte en realidad con el auxilio de la tecnología, pero con riesgo a ser sustituido por el «juez omniartificial», con sabiduría e inteligencia inigualable, cuya razón supera el error y el atavismo humano, perfecto y perfectible con datos lógicos y objetivos que combinan algoritmos matemáticos para 
acercarse a la combinación neuronal, lejano de preconcepciones y contaminaciones de experiencias vividas, esto es, la esperanza de una justicia tecnificada. Sin embargo, la función de sentenciar es especial y técnica cuando se trata del llamado delito como la conducta u omisión que sancionan las leyes penales y que ocasiona un daño a otras personas y tiene por consecuencia una pena, por mencionar términos involucrados. Para ejercerla se requieren características específicas, más allá de un documento físico o electrónico cargado de tecnicismos por materia, puesto que la sentencia penal representa una labor especial, distinta al resto de las materias jurídicas, y por eso es importante el análisis del impacto de quien la dicta y en la persona sobre quien se dicta.

El ius puniendi, o derecho de imponer pena, como facultad exclusiva del juez penal implica el ejercicio de su función ya sea como «mantenimiento de la norma como modelo de orientación de contactos sociales» (Jakobs, 1995: 12) o en un sentido preventivo general al momento de la consecuencia en el derecho penal objetivo, así como preventivo general y preventivo especial al momento del dictado de la sentencia y en la resocialización como efecto de la ejecución (Roxin, 1997: 3, 33 y 53); así contribuye en la rectoría del Estado con el fin de perseguir el bienestar común y la reducción de violencias. Por eso es vital la funcionalidad de quien sentencia, pues la instancia final de servicio es la sociedad y en ella se legitima, aunque ello pareciera cuestionarse en un contexto en el que los jueces, en tanto representantes del Estado, están constantemente sujetos a la condena social por el sentido de los casos que resuelven, ${ }^{24} \mathrm{y}$ es por esto que parecería necesaria la intervención tecnológica para auxiliarlos o sustituirlos.

Por otro lado, la informática jurídica está a la vanguardia en sus tres subespecies: la documental, la de gestión y la decisoria, siendo esta última la que permite tomar decisiones jurídicas por medio de la máquina (Guibourg, 2015: 798-80o), insertando desarrolladores predictivos en un trabajo que correspondía por completo al humano con la pretensión de corregir su accionar. La oferta de los procesadores predictivos de decisiones es sorprendente: ayudan al juez a vincular los datos de las personas con los resultados de las evaluaciones individuales y elaboran planes de tratamiento e informes de progreso a largo plazo, al tiempo que ofrecen una funcionalidad crítica para

24. Hay casos mediáticos donde la resolución judicial es representativa de una buena o mala actuación por la sociedad. Entre varios ejemplos destacamos casos como el ocurrido en México por la libertad de setenta y siete implicados en el caso de la desaparición de cuarenta y tres estudiantes de la Normal de Ayotzinapa, en Iguala en 2014 (véase El financiero, 15 de septiembre de 2019, disponible en https:// bit.ly/2 $\mathrm{TfH}_{9} \mathrm{Gz}$ ); o el caso llamado «Los porkys», donde el juez concedió amparo contra una orden de aprehensión a uno de los involucrados en el abuso sexual a una menor (véase El Universal, septiembre de 2019, disponible en https://bit.ly/3jk $3 \mathrm{CdK}$ ) y que fue comparado con el de «La manada», ocurrido en España (Véase Sentencia 344/2019, Tribunal Supremo, 2019, disponible en https://bit.ly/3snhNlY); y, finalmente, el caso de Edgar Tamayo en Estados Unidos por una condena de pena de muerte (Véase Informe 44/14, CIDH, 2014, disponible en https://bit.ly/3tpi8pF). 
la creación de informes de investigación previos a la sentencia y un administrador de carga de trabajo integral; ${ }^{25}$ asimismo, una productividad de mejora del $300 \%$ en promedio y de 2.700 casos, selecciona los urgentes de noventa y seis días a dos minutos, es decir, aumento de eficiencia del 90\%;también automatiza el proceso de creación de resoluciones, realizándolas en cuatro minutos (Estevez, Fillottrani y Linares, 2020: 63 y 69). En su uso para generar notificaciones de la Corte Interamericana de Derechos Humanos (CIDH), se realizan más de cien notificaciones en menos de dos minutos, dirigidas a embajadores y funcionarios de distintos Estados, en los cuatro idiomas oficiales de la Corte (español, inglés, francés y portugués), así como confeccionarla en cuatro minutos, cuando manualmente se necesita no menos de una hora. La herramienta de búsqueda avanzada permite realizar una investigación completa en base a las sentencias anteriores de la Corte en menos de dos minutos. ${ }^{26}$

La informática jurídica sin duda ha evolucionado en el imperativo tecnológico «si puede hacerse, debe hacerse», a diferencia del imperativo ético que justamente cuestionaba esta tecnicidad humana (González, 2004: 37) y que pareciera aproximarse al contexto normativo del derecho en el que, ya desde la creación del concepto de derecho informático en los años sesenta por Wilhelm Steinmülle, se vislumbraba la necesaria relación del derecho con la tecnología con objeto de su regulación, esto es, a partir de legislación que impidiera el abuso de la tecnicidad al punto de capacitar la propia destrucción humana. No obstante, algunas de estas discusiones se centraron más en la forma que en el fondo, es decir, prefirieron abocarse a plantear si debía considerársele o no rama autónoma del derecho en vez de a una comprensión de la tecnología como área ajena al propio derecho (Olivera, 2010: 509-510).

A pesar de que la utilización de sistemas de informática ya era común en muchos países, la situación de pandemia por Covid-19 declarada el 11 de marzo de 2020 por la Organización Mundial de la Salud, ${ }^{27}$ profundizó el papel del gobierno electrónico tanto en la prestación convencional de servicios digitales como en los nuevos esfuerzos innovadores para gestionar la crisis, pero también ha puesto en evidencia desafíos y múltiples formas de brechas digitales, especialmente entre los más pobres y los grupos más vulnerables según la encuesta de gobierno electrónico de las Naciones Unidas. ${ }^{28}$ En este contexto el gobierno electrónico, como nueva forma de gobierno que utiliza las tecnologías de la información y comunicación (TIC), en sus modalidades de gestión, planificación y administración, tiene como objetivo mejorar

25. Véase «Northpointe Suite case manager», Equivant, disponible en https://bit.ly/3cGMZXo.

26. Véase IALAB, disponible en https://bit.ly/3xoiYVj.

27. Véase Organización Panamericana de la Salud, 11 de marzo de 2020, disponible en https://bit. ly/3ghGgGn.

28. Véase United Nations, E-Government Survey 2020, «Digital Government in the Decade of Action for Sustainable Development», disponible en https://bit.ly/3wmBPQq. 
los servicios e información ofrecida a los ciudadanos, mejorar y simplificar los procesos de soporte institucional y fomentar la transparencia y la participación ciudadana (Villanueva, 2015). Esto ha significado que la oferta de la IA sea más atractiva aún en los espacios de justicia penal; en tanto que el juez puede ofrecer conocimientos especializados, la IA probablemente ofrezca trabajar conjuntamente con el humano para utilizar su especialización u optar por seguir perfeccionándose y especializándose para trabajar sin la intervención humana y ofrecer sus servicios al Estado con una eficaz utilización del aprendizaje automático, donde los precedentes y el contexto del caso son elementos para ofrecer una decisión judicial. ${ }^{29}$ Una vez contratado uno u otro, su institucionalización tiene diferentes rumbos.

El juez humano ha demostrado un comportamiento institucional que pone en duda su nombramiento, ya que se asume para juzgar cualquier acto humano regulado como delito bajo la protección de una burocracia administrativa y organizativa aprovechada para un «abuso de poder». ${ }^{\circ}$ Con intento de subsanar estos frenos se están generando reformas integrales al Poder Judicial que protejan la autonomía, la imparcialidad y seguridad de los jueces y magistrados, de acuerdo al relator especial de la ONU sobre la independencia de magistrados y abogados, y, con ello, aún la esperanza de conservar la función judicial en manos humanas sigue siendo real.

Puede observarse la previsión de la IA para apoyar a la función judicial, todavía más, la modificación de la clásica estructura por reiteración del sistema de jurisprudencia para involucrar un sistema de precedentes, lo cual facilitaría el trabajo de la IA para la identificación de casos análogos al que resolverá. Con motivo del auxilio a la justicia, el desarrollo de la informática jurídica supera su regulación con el derecho informático puesto que la información jurídica se encuentra en la actualidad principalmente almacenada en las bases de datos y requiere ser tratada con técnicas, herramientas y métodos informáticos como la inteligencia artificial, los sistemas expertos y la metaheurística, entre otras, para obtener resultados que favorezcan el apoyo a la toma de decisiones desde el punto de vista jurídico (Batista y otros, 2019: 132).

Por otro lado, el procesador de IA representa un símbolo adicional de supremacía del sistema de justicia penal ante el destinatario para legitimar la función de control social de la violencia, un artefacto que combina con la imponente majestuosidad visual de los recintos de justicia, un templo sagrado donde la justicia tiene carácter secular y da vida al poder público, el cual se extiende más allá de los involucrados en el caso que se sigue (Barrera, 2012: 135). Si este dispositivo toma la decisión, habrá menos posibilidades de que el justiciable intente cuestionar la decisión en una apelación, puesto que la «perfecta» abstracción de su caso no la haría un humano «imperfecto»,

29. «Il giudice...», p. 9.

30. Hace énfasis en el nepotismo y demás actos cuestionables dentro del Poder Judicial donde obtienen prestaciones y sueldos superiores en promedio a la media nacional y que se referenció previamente. 
que incluso puede no haber intervenido en ella. Lo anterior aunado a la posibilidad de que, si el justiciable no entendía los tecnicismos jurídicos, menos comprenderá la traducción algorítmica que haga de ellos el procesador, por lo que requerirá un especialista en derecho y otro en programación para imponerse de la sentencia y, por tanto, la relación entre el justiciable y el decisor de segunda instancia será indirecta. Se trata así de un proceso extraño, ajeno al deber moral de juzgar y a la interacción entre personas; un ritual técnico que funciona a partir de los sistemas expertos que estructuran conocimientos especializados en términos jurídicos y que, acoplados a un mecanismo de inferencia, extraen conclusiones de información suministrada de esta área del conocimiento en forma de preguntas y respuestas (Batista y otros, 2019: 132). Ahora el caso puede tratarse de tecnología resuelto por tecnología: un tribunal digital $^{31}$ de un orden superior al que no pertenece la mayoría de los excluidos, solo aquellos que utilizan la tecnología porque tienen acceso $y$, por supuesto, los pequeños grupos que la controlan; una justicia diferenciada en favor de las minorías poderosas pero que simbolizan el poder económico de un país.

Aun con ello, la característica que será decisiva para que la máquina «ayude»al humano o lo sustituya es la subjetividad como una característica innata del ser humano y por tanto del juez; esta característica de diferenciación es biológica y de aprendizaje experiencial a partir de los grupos sociales con los que interactúa, de inicio, la familia. Su conocimiento es alimentado y estructurado por interiorización de cánones éticos que sesgan necesariamente el caso a una visión propia, y que, por tanto, en una aplicación positivista del ordenamiento jurídico, lo adecuan a la decisión ya previamente formada. Así, la capacidad técnica del humano perfecciona las sentencias haciendo clasificación de temas y tiene por resultado que la preconcepción sea individual y también la decisión judicial.

Por otro lado, la aparente objetividad que presupondría el software llamado de IA por constituir datos matemáticos que parecieran ser exactos, intenta imitar los procesos inductivos y deductivos del cerebro humano a partir de circuitos electrónicos y programas avanzados de computadora que simulan las redes neuronales humanas (como Deep blue, Watson, Project debater y DeepMind, o en el clásico test de Turing). Con ello se comprobó que la argumentación sobre situaciones sociales era

31. Como el caso de la plataforma ahora en uso acerca de los contratos inteligentes escritos en blockchains donde al mismo tiempo se crea el tribunal digital que sustituye el papel de la aplicación de la ley en el paradigma tradicional de diseño de mecanismos y que demuestra que cualquier acuerdo que se puede implementar con aplicación legal también se puede aplicar por la corte digital, la cual tiene un equilibrio único siempre que haya una fracción positiva de comportamiento de los agentes, y da un juicio correcto en el equilibrio entre agentes honestos y deshonestos. Véase H. Matsushima y S. Noda, «Mechanism Design with Blockchain Enforcement», 14 de marzo de 2020, disponible en https://ssrn. com/abstract $=3554512$. 
una realidad para la máquina plagada de procesadores conectados entre sí, capaz de analizar oraciones y procesar principios de cómo los humanos piensan el argumento para construir la narrativa lógica del debate.

En el marco del positivismo jurídico se requería objetividad para la aplicación de la ley, sin embargo, ahora es exigible un razonamiento libre y de convicción, cuya discrecionalidad sea controlada con parámetros de decisión. Si bien se trata de un asunto complejo, debido a los principios de convencionalidad e interpretación extensiva, se espera que el juzgador se involucre en el caso más allá del formalismo y compostura de una sala de audiencia. La interacción en el recinto de justicia tiene su base en un evento doloroso y el juez, de acuerdo al principio de inmediación, tiene el deber de observar y escuchar a los justiciables; este principio, que tradicionalmente se manifiesta siempre y cuando haya presencia física real del juez, los sujetos procesales y órganos de prueba, no admite medios ni intermediarios, pero en la actualidad no solo debe entenderse como la relación real y directa, sino también la relación virtual generada por los entornos informáticos y entre los actores de un juicio oral o un acto procesal que se encuentran en lugares geográficamente distantes (Tayro, 2016: 554), que reconozca en ellos la esencia que comparten y que animaría al juez a responsabilizarse por trasformar positivamente sus vidas.

Por otra parte, a pesar de que el aprendizaje automático puede «pulir» matemáticamente la subjetividad humana con la selección de casos «correctos» que servirán como patrón para la decisión del nuevo caso, la esencia de este aprendizaje por capas para la decisión penal trata de experiencias exclusivamente humanas, violencias entre humanos, algo difícil de comprender para el propio humano. El deep learning, a pesar de lo simple que es (Chollet, 2018), requiere un espacio dimensional muy amplio que capture el alcance de los datos originales, es decir, que logre ver la realidad tal como la interpreta el ser humano. Por eso las llamadas «redes neuronales» no tienen nada que ver con el cerebro humano y el término correcto debería ser «aprendizaje de representaciones en capas o aprendizaje de representaciones jerárquicas, o tal vez incluso modelos diferenciables profundos o transformaciones geométricas encadenadas» (Chollet, 2018: 117).32

El deep learning corre el riesgo de ser sobreestimado a partir de los intentos de antropomorfizar malinterpretando las técnicas, al punto de creer que la máquina predictora entiende y comprende sus propias decisiones igual que el humano que lo hace con experiencias sensoriomotoras. Las máquinas predictoras son fácilmente engañables debido a que los resultados que arrojan solo dependen de los datos de entrada, que en el caso de las sentencias penales serían ejemplos de sentencias previas y esos datos solo se adaptan al nuevo caso; sin embargo, es distinto a lo que ha desarrollado

32. Traducción propia del inglés: «layered representations learning or hierarchical representations learning, or maybe even deep differentiable models or chained geometric transforms». 
el humano durante su vida, los momentos vividos están fijos en su mente y forman parte de su percepción y preconcepción.

En el intento de emular las interacciones humanas, la contraposición del humano al «ver el rostro del otro» - su alma a decir de Lévinas- (2015), el desarrollador Faception33 asegura analizar la personalidad facial de una persona con métodos de aprendizaje automático que van más allá de la biometría y que permiten realizar detecciones predictivas y acciones preventivas. Con solo analizar la imagen facial de una persona revela automáticamente su personalidad para hacer diagnósticos basados en imágenes de género y edad precisos, todo para mejorar la interacción personal con su propietario; puede calificar a las personas como introvertidas o extrovertidas con tendencia a ser compasivas y cooperativas y permite enfocar a los posibles terroristas y criminales antes de que hagan daño, todo ello con la promesa de objetividad y precisión. Este modelo lombrosiano supera en gran medida el intento de la atractiva morfopsicología que ha sido criticada como pseudociencia. ${ }^{34}$

El juez humano y la máquina comparten subjetividad, la máquina filtra y convierte el dolor en datos, el humano lo percibe, lo siente y lucha contra ello para no sesgar su decisión, por lo que valdría alejarse de atavismos legales y contemplar el valor primario de justicia en el caso con la más amplia sensibilidad y empatía con el dolor, entendiendo antes de juzgar las causas generadoras del actuar dañoso. Si es impuesto de un auxiliar tecnológico, el juez humano debe revisar con cautela los datos arrojados y, con la experiencia en sus roles, detectar posibles fallas o datos incompletos para complementar con un panorama muy cercano a la realidad del caso.

Sin embargo, y a pesar de la existencia de la interpretación extensiva, libre y lógica al dictar una sentencia penal, el juez aún tiene restricciones legales y parámetros de decisión que limitan la discrecionalidad al exigírsele actuar con convicción solo legal a partir de las pruebas desahogadas por las partes en juicio, bajo riesgo de revisión de su caso por un superior. A pesar de la justificación legal de no sesgar la decisión a la preconcepción, la libertad sigue sin existir y el velo que nubla la justicia permanece intacto. Esta imposición de control de subjetividad es una atadura del ente abstracto - el Estado - al individuo que reafirma con la idea de una supuesta ayuda administrativa, que no es más que un software controlador del probable riesgo de sesgo por parte del juez humano derivado de la multiplicidad de roles sociales que dirige el sentido de su sentencia y estorba al Estado.

Las experiencias directas e indirectas de violencia quedan tatuadas en la mente decisoria. Estas experiencias son distinguibles, por ejemplo, si se trata de una jueza

33. Para más detalles del desarrollador de IA, consultar su página, disponible en https://www.faception.com/.

34. Ver Javier Torregrosa y Rocio Payá, «Así es el rostro de un criminal», Noverbal, 2017, disponible en https://bit.ly/2GeAczp. 
mujer y un juez hombre, pues ella, envuelta en un contexto cultural-social patriarcal, ha alcanzado el rol de juzgadora, por lo tanto su función tendrá un sentido diferente al del varón, sobre todo tratándose de distintos tipos de violencias derivadas de estereotipos que se adjudican al «sexo débil», aunque a juez y jueza corresponda esta responsabilidad de acuerdo al Protocolo para Juzgar con Perspectiva de Género (Suprema Corte de Justicia de la Nación, 2020a); esto aunado a las resistencias administrativas de la institución que lentamente se va amoldando a la paridad de género. Este ejemplo es similar en la esencia interpretativa si el juez es indígena o pertenece a otro grupo vulnerado de la sociedad.

La institución a la que representan los jueces, y por la cual ejercen decisiones, es resultado de un desarrollo social y profesional que se tradujo en experiencia (Berger y Luckmann, 2001: 87). Esto nos previene del peligro de suponer que todas nuestras preferencias están basadas en algún criterio racional absoluto llevándonos a decir que «los valores constituyen una elección individual y son el motor de la personalidad del ser» (Sanabria, 2009: 909), pues cada individuo toma sus decisiones en función de la vida que lleva y de las necesidades que tiene, ya que no se puede decidir sobre algo que se desconoce dado que aquella es extraña para su realidad y por tanto incomprensible, pero se espera que la dignidad refleje empatía con el dolor por el daño del delito y de esta forma se fortalezca el deber de juzgar con valor de justicia.

La atadura es la posibilidad coartada del hacer; la libertad y la autonomía de la voluntad son innatas en el ser humano, al tiempo que su raciocinio es ilimitado y por ello superior al del Estado, por lo que este debe limitar el accionar del juez, asegurándose que cumpla su función punitiva sin anteponer su subjetividad, es decir, evitando que aplique una venganza privada «legal». Aun así, el juez o la jueza humanos no pueden evitar romper esta regla, su subjetividad le impone reconocer lo que ha interiorizado como bueno y malo ya sea por convicción o por conveniencia.

La libertad y la autonomía de la voluntad no existen en un procesador, porque es el humano quien introduce los datos de inicio para que ocurra el proceso de combinación algorítmica y luego su actualización. Sin embargo, el aprendizaje, que llega a ser autónomo, ejerce su libertad técnica y toma de decisiones sin intervención humana. Aun así, hay que considerar que, si de delitos se trata, la legislación es modificada constantemente debido a la actualización de supuestos dañosos, ya que, al contrario de la capacidad finita del procesador, el cerebro y la mente humana comprende, entiende e imagina la acción de otro semejante que daña. Para los programadores representa un reto emular el delito con base en la ley y los antecedentes de conductas violentas resueltos por las autoridades para que la máquina realice el aprendizaje y tome decisiones, sin embargo, si las conductas que definen los delitos varían caso a caso y por tanto su resolución, los datos de entrada poco ayudan a la exactitud de decisión algorítmica. En el juez humano la capacidad es natural y por ello crea decisiones de manera inconsciente, tal como lo hace un novelista (Posner, 2011: 77). 
La persona con finitud física e infinitud mental no evade la responsabilidad de la justicia, puesto que el juez en este rol comparte con el destinatario la comprensión de su significado. La máquina intenta abstraer del humano tal comprensión y la traduce en algoritmos matemáticos para objetivarla, consiguiendo un resultado que no es el mismo que para el humano, porque la interpretación en el deep learning no es la misma que la que el humano toma de la realidad, es decir, el significado de justicia no será el mismo para el software que para el humano. La justicia es un término abstracto imposible de definir matemáticamente, tiene que ver con la esencia del ser y su relación con la sociedad: «El derecho no es revelado por Dios ni descubierto por la ciencia, es una obra plenamente humana en la que participan quienes se dedican a estudiarlo y que no pueden interpretarlo sin tomar en cuenta los valores que transmite: compartir un mismo deber ser con la sociedad» (Supiot, 2007: 28).

La llamada «inteligencia artificial», lejos de ser autónoma y objetiva, está impregnada de situaciones humanas, contextos comunitarios e individuales desiguales que son base para la decisión judicial. El resultado, parecido al de la subjetividad humana, está alejado de toda sensibilización y comprensión de ese bagaje de elementos sociales, e incluso corre el riesgo de cometer errores de traducción al algoritmo, cuando además pueda no corresponder con lo descrito en la ley. El humano, por el contrario, tiene experiencias de vida, está envuelto en una cultura y procesos de resiliencia que ponen a la vista del juez contextos ajenos a su propia realidad que, aunque les sean desconocidos, tienen la posibilidad de provocar su sensibilización al punto de adecuar su pensamiento crítico más allá del mandato legal, es decir, tiene la posibilidad de un amoldaje más justo que correcto.

Solo el ser humano es autónomo y completamente subjetivo, por tanto, libre, y ello es lo que representa su dignidad. La dignidad es la diferencia sustancial con el software y de la cual se anteponen al Estado los derechos fundamentales. La actividad de sentenciar debe orientarse por la búsqueda de una mejor vida en sociedad y, más allá de la punición, supone comprender las causas del delito, así como el dolor de quien lo sufrió, con el fin de acceder a sus significados culturales y no tan solo desde la perspectiva de las leyes penales. Sentenciar significa reconocer en los justiciables su dignidad y, a partir de ello, identificar la falta de garantía de los derechos humanos por parte del Estado, con miras a que la medida reactiva tenga una función transformadora, preventiva y de no repetición.

\section{La justicia penal humana: Una reconfiguración de la función judicial de sentenciar}

Una sentencia penal construida bajo una visión puramente positivista implica un razonamiento lógico formal del juzgador, cuya labor es la subsunción del hecho al tipo penal establecido por el legislador, puesto que, bajo un modelo estructural dogmático 
de teoría del delito, el principio de exacta aplicación de la ley penal que distingue al derecho penal estaría descrito en el apotegma nullum crimen, nulla poena, sine lege. Sin embargo, al delimitar la individualización de la pena, el contexto y las características particulares del sujeto activo, la criminología clínica (Manzanera, 2005) definió un tipo de sujeto cometedor del delito: un ser asocial que tenía que ser estudiado y tratado para «convertirlo» en un ser social. En consecuencia, se buscaba que la motivación y fundamentación de la sentencia, así como el sentido de la pena, fueran acordes a esta visión. La criminología crítica (Baratta, 1982) puso en debate la finalidad de la pena y las funciones latentes del Estado con su sistema de justicia penal pues, como pudo observarse en Presunto culpable, ${ }^{35}$ el Estado selecciona conductas que convierte en delitos, así como personas que convierte en «delincuentes». El ius puniendi, que responsabiliza y castiga a una persona, no es aquel que representa la justificación racional del Estado y que hace la diferencia con la venganza privada.

Por otro lado, el avance de la teoría del derecho se hacía presente en el derecho de la posguerra, cuando la reconfiguración del orden jurídico modificó su sentido en función del reconocimiento de los derechos humanos que las constituciones hicieron tangibles con los derechos fundamentales. El llamado neoconstitucionalismo implicó reconocer la ductilidad del derecho (Zagrebelsky, 2013) y, por tanto, un orden jurídico imperfecto con lagunas y antinomias normativas contrapuestas a principios provenientes del reconocimiento de los derechos humanos, haciendo necesaria una interpretación material normativa del ordenamiento legal. Así, las teorías penales tenían sus contrapuestos: el derecho penal del enemigo (Jakobs y Cancio Meliá, 2006), que conservaba una visión etiquetadora del sujeto activo del delito, y el derecho penal mínimo, con una propuesta preventiva del derecho penal punitivo consistente en la reducción de comisión de delitos y de penas excesivas (Ferrajoli, 1995) para que solo en el escaso número de comisión de delitos se aplique la mínima pena. Debido a que los derechos fundamentales son antepuestos solo al Estado, entonces la responsabilidad de la mínima aplicación punitiva solicita afinar la motivación y fundamentación con el contexto, no solo actual sino previo al delito, que justifique, en caso de condena, la afectación de los derechos fundamentales de la persona declarada responsable de un hecho delictivo a partir de un debido proceso en el cual la víctima es parte esencial y a quien también deben ser garantizados dichos derechos. Cuando algún elemento quede fuera de los estándares legales de derechos humanos, el acceso a la justicia internacional está disponible.

Fue pertinente la teoría de Robert Alexy (1993) a propósito de la complejidad de la interpretación convencional de principios optimizables derivados del reconocimien-

35. Roberto Hernández y Layda Negrete (directores) (2008), Presunto Culpable [Película documental]. Abogados con Cámara; Instituto Mexicano de Cinematografía Conaculta; Fondo para la producción cinematográfica (Foprocine). 
to y respeto a la dignidad humana y los derechos que de ella resultan reconocidos por los órdenes jurídicos continentales. El ejercicio metodológico se basa en diferenciar las características de las normas y de los principios para hacer la distinción aplicativa al caso concreto y reconocer conflictos entre normas, normas con principios, así como principios con principios. La propuesta teórica alexyana para tal ejercicio guió a los jueces para decidir los casos concretos bajo una nueva concepción de derecho. La discusión teórica actual resalta que los principios no son fáciles de diferenciar de las normas, más aun tomando en cuenta que los principios pueden ser implícitos y explícitos y, por tanto, configuran el caso de forma abierta, mientras que las reglas lo hacen de forma cerrada, de tal manera que el grado de indeterminación de los principios en relación con las reglas es mayor (Atienza y Ruiz, 1991: 108), lo que constituye ampliación de discrecionalidad en la argumentación penal potenciadora de principios. El constitucionalismo principialista se diferencia del garantista porque deja abierta la interpretación a evaluación de hechos con base en principios que pueden no estar expresos en el ordenamiento jurídico (Ferrajoli, 2011).

El panorama para la construcción de la decisión penal no solo es incierto jurídicamente, sino que pone en duda la esperanza de justicia, por un lado, en la responsabilidad de señalar a una persona responsable de un delito, imponiéndole un cuanto de pena y, por otro, declarar a otra persona víctima y señalar la reparación del daño. La motivación y fundamentación en el ejercicio ponderativo se complejiza además con la contextualización del caso y la multiplicidad de legislación alterna nacional e internacional y el conocimiento multidisciplinar se torna vital para la interpretación extensiva por la necesidad de interiorizar los elementos del caso y las situaciones particulares de los justiciables para aplicar justicia diferenciada acorde a las vulnerabilidades que presenta una sociedad desigual.

En las últimas décadas el escenario de reformas a la justicia penal en América Latina tuvo como tendencia la regulación de salidas alternativas al proceso tradicional, sin embargo, a pesar de la intención de contribuir a un mejoramiento de la justicia, los mecanismos de control han sido insuficientes para su adecuado tratamiento (Rua y González, 2017), por ello es que la sentencia penal continúa siendo representativa de la certeza jurídica reflejada en decisiones de casos que pueden ser sometidas a evaluación nacional e internacional. ${ }^{36}$

36. La revisión de la sentencia está presente en las instancias correspondientes nacionales o incluso internacionales a efecto de la revisión del debido proceso. Como ejemplo ilustrativo nacional, en México la sentencia de primera instancia del caso seguido por feminicidio de Rubí Marisol Frayre fue representativa del inicio de la reforma al sistema penal acusatorio, la cual fue absolutoria por la llamada «duda razonable», y en apelación fue condenatoria con cincuenta años de pena privativa de libertad, lo cual puso de manifiesto que la función de los jueces al valorar la prueba estaba en proceso de construcción, pero también que estas pruebas dependían de un proceso previo donde la responsabilidad de la función investigativa tenía esos efectos (véase Ríos, 2012: 415-416). En un ejemplo de caso internacional, la Corte 
A pesar de que la idea inicial de creación de la inteligencia artificial fue auxiliar al humano en sus tareas cotidianas, parecería que ahora teme ser desplazado por su creación e intenta sin éxito controlar su tecnicidad. Hay muchas sentencias penales destructivas dictadas por los humanos y parecería que la participación activa de los softwares predictivos daría esperanza a los justiciables y a la sociedad de un acercamiento a la justicia. Pero el fin constructivo de la verdadera función judicial penal inicia con identificar y reconocer algunos elementos que le darán configuración.

\section{La técnica}

Reconocer que la función de sentenciar es una capacidad humana utilizada como medio para el fin de la justicia, o al menos esa es la intención, pero es también valioso reconocer que el resultado ha sido lo contrario. Hemos revisado en los párrafos anteriores lo complejo que resulta la elaboración de una decisión judicial penal, pero la técnica humana tiene posibilidad infinita de simplificar lo complejo tan solo con un esfuerzo material y secundariamente formal. «La técnica es libertad cuando recordamos que estamos frente a un medio, un medio muy complejo, pero tan solo eso. Los fines debemos decidirlos nosotros. Es decir, nuestra libertad depende de que seamos capaces de hacer valer los fines de cada uno, como seres humanos, a través de la técnica, del arte, del deporte, o de la vida cotidiana» (Lefranc, 2016: 45). Sin embargo, sin darnos cuenta y antes de reflexionar, la tecnología a partir de un objetivo de mercado nos deslumbra con productos sorprendentes.

Probablemente los predictores de sentencias aligeren la carga del juez y tal vez proporcionen datos y leyes que no tenía contemplados, tal vez también es conveniente al Estado para restablecer su legitimidad rota, pero $\iota^{\text {es }}$ conveniente a la dignidad de los justiciables y a la del propio juez? ¿ ¿En realidad el predictor produce justicia? « $\mathrm{Si}$ el ser humano es la única esencia que puede hacer fuego, entonces... ¿Se puede verificar la eficacia de la orden que se emite con un clic? Porque solo así sabemos si la idea de una justicia que pueda ser lograda en una sociedad virtual tiene un verdadero sentido, o si es tan solo que el imaginario ha consolidado ya esta idea» (Lefranc, 2016).

Sin embargo, hay fines distintos y los ofertadores de softwares, con objetivo de mercado, muestran sus productos con discursos de ayuda a las personas, pero lo que les importa por supuesto es el contrato para asegurar la ganancia. Se obligan al mismo tiempo a innovarlos constantemente pues otra empresa puede «ganarle» al com-

\footnotetext{
Interamericana de Derechos Humanos resolvió que un caso que las autoridades peruanas habían archivado desde 1995 se abriera y se dictara sentencia, la cual en 2008 fue pronunciada como condenatoria por la muerte de dos mujeres y las lesiones de gravedad a un tercer sujeto por un disparo de un soldado en Lima. En este caso el mecanismo legal puesto a debate y por el que se había resuelto el archivo del caso fueron las Leyes de Amnistía 26.479 y 26.492, las cuales resolvió la Corte como incompatibles con la Convención Americana (véase CIDH, 2014).
} 
prador. «Dominar la naturaleza, enseñan los imperialistas, es el sentido de toda técnica» (Agamben, 2006). El hacer, entonces, es la forma de la técnica, pero la misma teoría y filosofía jurídica, así como la del derecho penal, están cambiando de rumbo con incertidumbre, pero con el sentido de no dañar más de lo que han sido dañadas las personas, el derecho penal es lo no deseado si el fin es punitivo, pero el derecho penal mínimo ofrece aplicar al menos un poco de daño. Así, entre la protección a la dignidad y la vulneración de derechos humanos, el panorama se observa difuminado incluso dudando de la existencia del derecho.

Surge la tecnología con resultados sorprendentes a tratar de esclarecer el panorama desde las ciencias exactas, demostrando que las matemáticas son estructura perfecta y pueden solucionar las realidades. El humano tiene una capacidad innata, imparable e infinita de crear. Crea sentencias, pero no utiliza totalmente esta capacidad en la imaginación, porque la mecanización ha sido una costumbre judicial donde se limita la libertad humana y el juez se ha autoasumido como aplicador de normas. La llamada «inteligencia artificial» no representa la totalidad de la capacidad del cerebro y tampoco la de la mente para crear. La técnica no determina al humano y el derecho tampoco es el límite de la técnica.

\section{La función punitiva del derecho penal}

Los derechos humanos han sido pensados en una lógica normativa al introducirlos en las Constituciones, pero el interpretarlos representa complejidades para los tribunales. Ha hecho falta un paso previo, repensarnos en lo individual y colectivo bajo una lógica de cuidado más que de obligaciones y deberes para entender que la positivación de los derechos humanos es solo una guía que rememora lo crueles que hemos sido como humanidad, pero al mismo tiempo, la capacidad que tenemos para reencontrarnos - en esencia de dignidad.

El derecho penal, como antítesis del buen comportamiento esperado por el orden jurídico, sanciona la responsabilidad penal en virtud del ajuste de ciertas conductas con hechos descritos como delitos en la ley, esto es, aquellos que vulneran derechos tutelados por el Estado, el llamado «bien jurídico tutelado» (Zaffaroni, 1998: 46 y 58). Es por ello que sus límites son principios positivistas aún vigentes, como el de exacta aplicación de la ley penal, que establece que su fuente de producción determine las conductas a sancionar conforme a la descripción general que más se ajuste a los casos de la realidad, o el principio de fragmentariedad, según el cual solo se seleccionan como punibles las conductas más graves dentro de la multiplicidad del universo total, lo que es conocido como criminalización primaria (Zaffaroni, Alagia y Slokar, 2006: 11). Sin embargo, las constantes modificaciones a las descripciones típicas, o la adición de algunas nuevas, da cuenta de la infinitud de conductas y modos de cometerlas que tiene la capacidad humana. 
No ampliamos nuestra visión al pasado-ese que nos dio vida - con el presente, ni siquiera tenemos una identidad ni nos definimos, no sabemos quiénes somos y desplegamos nuestro atavismo contra las personas, esas que tienen una misma cultura y pasado, que conocen los sufrimientos del ser social en las desigualdades; esta identidad parecería eliminada y es la oportunidad de la conquista: monopolio y adoctrinamiento. Pensamos que la verdad es aquello en lo que creemos aunque no dimensionemos que fue impuesto; esta era la misma justificación en el Holocausto, como lo explica Bauman (1989: 45): «Las víctimas de la violencia están deshumanizadas como consecuencia de las definiciones ideológicas y del adoctrinamiento».

\section{El monopolio del control de la violencia}

La idea de que el control de la violencia es una función rectora del Estado es una creencia que nos ha mantenido como ciudadanos en una relación de subordinación con él, teniéndolo como símbolo de autoridad y representatividad legitimado para sentenciar penalmente como resultado de movimientos revolucionarios que crean un orden y ordenamiento constitucional. No es así, y al ver los resultados de la justicia penal y el significado de "primer mundo» que tiene un país con base en su economía, aquel movimiento de lucha que dio vida a una Constitución y al resto del orden jurídico queda destruido. La dinámica capitalista invita a los países a mostrar su competitividad económica a partir del uso de la tecnología y así es vista como una inversión necesaria, un gasto que les producirá mayores beneficios que los que pudiera tener si destinaran esos recursos a reducir desigualdades sociales como parte de su responsabilidad olvidada. Se apuesta a una hipótesis política, una nueva fábula que, a partir de la Segunda Guerra Mundial, ha suplantado definitivamente a la hipótesis liberal: «La hipótesis cibernética», a la que no hay que criticarla sino combatirla y vencerla (Tiqqun, 2015: 8).

El colonizador sector privado, creador de desarrolladores tecnológicos, desplaza al Estado en su función rectora de control de la violencia, instrumentalizándolo para que siga seleccionando personas y conductas para «jugar con ellas» y hacer cálculos para maximizar el beneficio. La tecnología, con lenguaje económico y matemático, cosifica a las personas y codifica su realidad, decide incluso qué es racional y qué no. Así, quien usa una computadora y aprende el lenguaje matemático y económico, es un ganador (Schirrmacher, 2014).

Probablemente los elementos identificados pudieran ampliarse o agregarse otros, pero los siguientes nos ayudan para una propuesta de reconfiguración del juez humano y su función ante la imposición de un software auxiliar predictor de sentencias o la sustitución de su actual función técnica. 


\section{Juez penal revolucionario}

La técnica y su esencia no determinan al juez puesto que tiene autonomía y libertad para racionalizar y tomar decisiones, es decir, el control de sí mismo. En cuanto el juez reconozca esto y se autoasuma valioso, su labor podrá convivir con la técnica que diseñó y creó al software. La técnica auxiliar de una máquina y la racionalidad sensible del humano no se contraponen. La superioridad humana radica en su infinito raciocinio y en la humildad de reconocerse como y entre personas, el temor desaparece pues proviene del ser y autoasumirse inferior, es decir, el miedo a ser aplastado.

El ser una persona subjetiva y falible no representa inferioridad, sino su definición parcial, que es complementada con la responsabilidad por el otro. Así, el juez tiene una responsabilidad que da sentido a su función y a su ser: transformar la vida de los justiciables, de cerca; una dignidad acompañada. El cuidado nos permite reconocernos en el otro y responsabilizarnos desde el simple saludo (Lévinas, 2015).

Un juez revolucionario es quién, no qué, es una persona libre para ayudar a sus semejantes y anteponerse al Estado y a la empresa, no como obligación, sino por vocación de la función y fuera de códigos de conducta que guían su actuar en el servicio público. En principio, el juez es quien dirige el sentido de la sentencia, porque «revivió» el dolor junto con los justiciables y reconoció las causas que los reunió y que ahora lo responsabiliza para mejorar sus vidas y sus condiciones. La labor del juez va mucho más allá de la que le impone un ente que le exige venganza solo para legitimarse; el juez entonces estará en condiciones de analizar el caso en lo particular y en lo colectivo, y es donde el procesador automático puede ayudar si es necesario: mostrando panoramas de realidades ajenas al juez, principalmente las que representan desigualdades y violencias, con el objetivo de aplicar una justicia diferenciada. El juez tendrá la oportunidad de sorprenderse y ser sensible al caso en el sentido que lo comprenden las partes. A partir de la introspección, la contemplación admirativa y la curiosidad de asombro, el thaumazein de Heidegger (Held, 2002: 64), hará una abstracción y estará en condiciones de crear; no solo eso, verificará cuáles casos existen aún en espera de sentencia e impulsará su avance procesal. El sentido de la sentencia es así una oportunidad de ayuda para transformar la vida de los sufrientes con una reparación integral más allá de una reparación económica. Se debe representar a la sentencia como una obra de arte tal cual lo es la vida, como una experiencia estética, original y auténtica (Gadamer, 2006). Esta autenticidad se define como poner la conducta dañosa en su justa dimensión, porque actualmente nos impresionan las violencias donde se masacran a los humanos, pero no aquellas donde el Estado es partícipe del daño a la ciudadanía, ${ }^{37}$ o las cometidas por las grandes empresas para extinguir

37. Por ejemplo, los delitos relacionados con la corrupción que siempre acompañó al capitalismo y 
elementos sociales identitarios que intentan mantener los pueblos indígenas ${ }^{3^{8}}$ y generan una macrodelincuencia donde los Estados son solo instrumentos de autores mediatos no estatales del actual totalitarismo financiero (Zaffaroni, 2019: 166). Solo pues con la sensibilidad podemos reconocer el verdadero daño.

El juez es quien debería acompañar a los justiciables a anteponer al Estado sus derechos humanos y exigir las condiciones específicas que orillaron a la comisión delictiva, pero, además, verificar su cumplimiento; de esta forma se empoderaría al justiciable y no se le estigmatizaría más. La sociedad tiene medios y mecanismos para que el individuo decida con autenticidad y exprese lo que «realmente es», libre de ataduras obsoletas como el adoctrinamiento religioso o la falta de recursos materiales. La justicia será transformadora cuando se mire a un mejor porvenir, reconociendo las causas, condiciones y violencias del pasado: mirar hacia adelante, viendo hacia atrás.

Las reglas de interpretación alexyana representan un grado de complejidad en su aplicación que puede dejar en duda la comprensión de justicia en los destinatarios de la sentencia y encuadran con formalismo el caso. El juez actuará como verdadera autoridad, como un fin en sí mismo y como un medio para lograr justicia en el otro; pero si se remonta a la causa que le dio vida al supuesto de violencia, ampliaría su panorama sesgado por la imposición del sistema de justicia penal y entendería las complejas dinámicas sociales y las desigualdades; más aún, si antropológicamente se reconoce en una misma comunidad a pesar de las distintas realidades, vería que tiene en común un mismo pasado que lo hermana con quienes piden justicia en «retrotopía» (Bauman, 2017: 14). Si la combinación algorítmica ayuda, será en mostrar el contexto superficial que hace la realidad virtual pero no en la historia, las experiencias las viven y sienten las personas y las transmiten de generación en generación. La interpretación de este legado no es posible definirlo matemáticamente, pues no es estructurable, como tampoco lo es el ser humano que lo vivió y lo transmitió, así como el que lo recibió.

frente a la que los Estados reaccionan con leyes para vender la ilusión de su eficacia preventiva, pero que en realidad crean una maraña normativa que abre la posibilidad de criminalización como nuevo ámbito de corrupción administrativa y judicial (Véase Zaffaroni, 2019:82-83).

38. Por ejemplo, los de daño ambiental como el de la minería en el contexto latinoamericano y la indulgente respuesta internacional a los métodos nocivos de explotación que conducen a la contaminación del agua, el aire, la flora y la fauna, y que generan igualmente serios problemas de salud de los trabajadores y las comunidades locales, como fue el caso del desastre humano y ambiental causado por Samarco Mineração S.A. (empresa mixta de capital brasileño, británico y australiano) en Bento Rodrigues, Brasil. En noviembre de 2015 el terraplén de la represa de Samarco colapsó, inundando a las comunidades locales con residuos tóxicos mineros, barro y agua. Los residuos contaminantes destruyeron un pequeño pueblo de seiscientos cincuenta habitantes y afectaron a más de una docena de pueblos ribereños en su camino hacia el Océano Atlántico, quinientos kilómetros más abajo. Más de veinte personas murieron (Véase Böhm, 2017: 39). 
En este contexto, la función judicial y la reemplazabilidad del juez humano son una utopía, puesto que el juez no sería más un mero aplicador de normas o experto en técnicas argumentativas, sino una persona cuya diferencia con el software es su capacidad de sentir, comprender y entender al otro a partir de interpretar su realidad como miembros de una comunidad al estar cumpliendo un propósito único, y que puede actualizarse dentro de los límites de la sociedad y no del Estado o la empresa.

La máquina puede detectar sentimientos y emociones por las palabras, pero no por el interior; el cuerpo engaña, la mente es impredecible. El humano tiene supremacía ancestral, pero el vínculo con lo material, lo visible, superó lo espiritual y olvidó el pasado que forma parte de su construcción histórica y por tanto la otredad. A pesar de la imposición de la máquina al juez penal, probablemente este lo acepte porque le ayuda un poco en su asumida inferioridad, porque se avergüenza de su pasado y evita ser visto como el bárbaro que realizaba prácticas sacrificiales a los dioses, aunque esto sea similar a la sentencia penal condenatoria, pero la diferencia es que aquellas prácticas tenían un significado divino (Alagia, 2013), cosa que hoy se olvida en la función judicial y que es necesario retomar, el decisor penal daría significado divino a su decisión. Esta es la verdadera evolución. El juez penal no compite con la máquina ni le debe temer, porque no lo domina ni lo determina, y no aceptará convertirse en el sirviente de alguien más. El ser humano tiene una nueva oportunidad de poner en práctica su capacidad de transitar de un actuar negativo a un actuar positivo, por ello no debemos ser escépticos frente a que la creatividad y la compasión, como características exclusivamente humanas, pueden aplicarse para una reconfiguración del juez humano.

\section{Evaluación por el resultado en los justiciables}

Las transformaciones e innovaciones en los sistemas de justicia penal tienen como destinatarias a las personas justiciables, por eso la evaluación de justicia les corresponde; no se trata de desdeñar a las representaciones estatales e internacionales, sino que la evidencia directa de la justicia está en quien la recibe. Pero quien la percibe, que es el resto de la sociedad y las instituciones que ayudan a verificar esa justicia y «acreditarla», es decir, avalarla porque participaron en su creación, tienen elementos para conocer los pasos dados. La interdisciplina por supuesto es importante para la interpretación temática del caso específico y para el ejercicio de la justicia diferencia$\mathrm{da}$ admitiendo incluso que personas de la misma comunidad pongan al juez el contexto de la desigualdad. El juez tendría una evaluación sobre su sensibilidad con el contexto y las personas porque sería un juez para y por las personas y no más un juez al servicio del Estado o de la empresa. La sociedad y los justiciables liberarían al juez de esta atadura y lo invitarían al misterio de sentir el dolor de la violencia sufrida; esto lo redefinirá como persona a cargo de otras y sentirá orgullo más que aquel sacrificio 
engorroso de escuchar y resolver todos los días «problemas de otros», aquellos vistos como los nuevos «enemigos» en el derecho penal de la modernidad avanzada y contra quienes se privilegia el control punitivo. El Estado se muestra no solo débil sino vacío pues el crimen como problema social palidece ante la privatización de buena parte del territorio de la justicia y de las políticas sociales (Tenorio, 2014: 13-15).

Se proyecta que las personas creativas son las que tienen asegurados sus empleos (Mercader, 2017: 158) y aquellos que quieran permanecer siendo solo aplicadores de penas quedarán sin trabajo porque una maquina lo hará mucho mejor que ellos. La ironía para el Estado y las empresas es que las personas que han sido vulneradas, excluidas y discriminadas, son las que han aprendido a crear para subsistir, por ejemplo, los campesinos y la medicina ancestral. La cultura y la decolonización son pilares de esto y resultaría también atractiva la participación de la IA para mostrarlo.

\section{La tecnología al servicio del juez penal humano}

Si la capacidad técnica de las personas debe estar al servicio de las propias personas y el Estado, que está a cargo del bienestar social, debe potenciar la creatividad de las comunidades, entonces el diseño, la creación e innovación de la tecnología estará a cargo de las personas de comunidades que conocen sus necesidades e interpretan su realidad.

La ONU tiene esperanza de que ocurra una redirección de las tecnologías hacia la ayuda social, cuestión que se ha dejado atrás y que debe suceder incorporando a las personas fuera de la lógica del mercado, pues de lo contrario no se tomarán en cuenta los derechos humanos y se continuarán favoreciendo nuevas formas de cometer delitos que llevan de la «hiperconectividad» a la «cibercriminalidad» (Asamblea General de las Naciones Unidas, 2019). Tenemos la esperanza de que se vaya construyendo con la tecnología un mundo mejor para disminuir la desigualdad y que la IA sea asequible a todas las personas de tal manera que sea entendida y comprendida, sean transparentes sus algoritmos y manejables para evitar la trampa y el sesgo. Ya se está trabajando en ello y esperemos se vean beneficiadas las sociedades.

El juez penal verá así menos casos de violencia y los que haya serán abordados con los contextos claros y no sesgados o malinterpretados, ajenos de la realidad de desigualdad y violencia. Así podrá hacer su obra de arte auténtica y original, creará con su infinita capacidad de imaginar una realidad mejor que la que ahora tienen los justiciables. Para este trabajo puede servir la tecnología como un simulador predictor de realidades mejores a partir de las manipulaciones del juez respecto al caso concreto. También requerirá actualizaciones conforme vayan siendo necesarias a las nuevas realidades. Con un sistema de transparencia de las peticiones al Estado para hacer exigibles las garantías de derechos humanos. Entonces la tecnología estará al servicio 
del juez humano y éste al servicio de sí mismo y los demás: «Quiero especializarme en ser un ser humano cálido y compasivo. Por eso necesitamos que la IA sea segura y demostrablemente segura». ${ }^{39}$

\section{Conclusiones}

Sentenciar tiene un significado distinto al declarado, representa responsabilidad social y empatía con el otro, con su dolor por el daño sufrido y las causas que originaron el evento trágico.

La tecnología ha transversalizado la vida cotidiana y para la función judicial ha resultado muy útil como herramienta eficiente y efectiva. Sin embargo, cuando se la pretende imponer al juez penal para que sea su auxiliar, este podría ser desplazado por el resultado comparativo del trabajo mecanizado.

Por eso, en el análisis del verbo «sentenciar» tuvo sentido la relación con su fundamento teórico de interpretación y el sentido del derecho, el cual epistemológicamente se encuentra en construcción. Los dos fines del derecho penal de acuerdo a Ferrajoli: prevención de delitos y penas excesivas, significan un reto estatal que implica la adopción de mecanismos sectorizados, principalmente en sociedades desiguales que favorecen la violencia. La aplicación de elementos fácticos y normativos para la fundamentación y motivación de la sentencia penal son complejos por la multiplicidad de conductas dañosas y personas sufrientes que, en su mayoría, son las vulneradas de la sociedad y no ven una expectativa de justicia diferenciada en las sentencias penales. Estas intersecciones superan al juez, pero también al software predictivo, porque el juez tiene experiencias de una realidad distinta a la de los justiciables, pero la máquina decisora no logra traducir matemáticamente la complejidad social al modo en que lo comprenden las personas. Por eso es que es factible para el juez interpretar esa realidad aun sin conocerla, y la tecnología será grandiosa si digitaliza esos contextos y culturas con imágenes en realidad virtual. Esto ayudará al juez a empatizar con el caso y crear una sentencia transformadora.

El juez penal humano nunca será reemplazado por las máquinas si se reconfigura; es urgente que se encuentre a sí mismo y se autodefina. Lo que falta al juez humano es huir del yugo del Estado y si no lo hace pronto será propiedad desechable de las empresas creadoras de tecnología. Al reconfigurarse, su función también se transformará para ser humana; al empatizar con las personas justiciables y su contexto, procurará que su resolución tenga un sentido transformador de vidas y alejado de lo punitivo con plena evidencia de evaluación de sus destinatarios directos. Pero, ade-

39. Eric Niller, «Can AI be a fair judge in Court? Estonia thinks so», Wired, 25 de marzo de 2019, disponible en https://bit.ly/36n5Mpo. 
más, su función se extiende al seguimiento de acciones de exigibilidad al Estado para garantizar condiciones sociales que eliminen o reduzcan las causas generadoras del delito conforme a su resolución. Una verdadera justicia penal por y para la sociedad.

\section{Referencias}

Agamben, Giorgio (2006). Lo abierto. El hombre y el animal. Buenos Aires: Adriana Hidalgo.

Alagia, Alejandro (2013). Hacer sufrir. Imágenes del hombre y la sociedad en el derecho penal. Buenos Aires: Ediar.

Aletras, Nikolaos, Dimitros Tsarapatsanis, Daniel Preoţiuc-Pietro y Vasileios Lampos (2016). «Predicting judicial decisions of the European Court of Human Rights: a Natural Language Processing perspective». PeerJ Computer Science, 2: e93. DOI: $10.7717 /$ peerj-cs.93.

Anaya, Miguel A. y José L. Anaya (2016). «La prueba ilícita y la regla de exclusión en la Constitución mexicana». El Cotidiano, 197: 28-34. Disponible en https://bit. ly/3ak8U6o.

ANDRÉs, Perfecto (2020). «Fisiología y algunas patologías de la sentencia penal». En Abril Uscanga y Carlos Humberto Reyes (coordinadores), Estudios contemporáneos de teoría y dogmática jurídica iberoamericana (pp. 113-147). Ciudad de México: UNAM. Disponible en https://bit.ly/3tuAkxZ.

Asamblea General de las Naciones Unidas (2019). La extrema pobreza y los derechos humanos. Disponible en https://bit.ly/3jpıDog.

Atienza, Manuel (1994). «Las razones del derecho. Sobre la justificación de las decisiones judiciales». Isonomía, 1: 51-68. Disponible en https://bit.ly/3oFIhiq.

Atienza, Manuel y Juan Ruiz (1991). «Sobre principios y reglas». Doxa: Cuadernos de Filosofía del Derecho, 10: 101-120. DOI: 10.14198/DOXA1991.10.04.

Bauman, Zygmunt (1989). Modernidad y Holocausto. Madrid: Sequitur.

-. (2017). Retrotopía. Barcelona: Paidós.

BARrera, Leticia (2012). La Corte Suprema en escena: Una etnografía del mundo judicial. Buenos Aires: Siglo XXI editores.

Batista, Noel, Corina Elena Navarrete, Carmen Magaly León, Manuel de Jesús Real, José Antonio Chiriboga y Jesús Ricardo Estupiñán (2019). «La toma de decisiones en la informática jurídica basado en el uso de los Sistemas Expertos». Revista de Investigación Operacional, 40 (1): 131-139. Disponible en https://bit.ly/3feYkR4.

Berger, Peter y Thomas Luckmann (2001). La Construcción Social de la Realidad. Buenos Aires: Amorrortu.

Böнm, María L. (2017). «Empresas transnacionales, violaciones de derechos humanos y violencia estructural en América Latina: Un enfoque criminológico». Revista Crítica Penal y Poder, 13: 41-65. Disponible en https://bit.ly/3iMcToR. 
Brennan, Tim, William Dieterich y Beate Ehret (2008). «Evaluating the predictive validity of the COMPAS Risk and Needs Assessment System». Criminal Justice and Behavior, 36 (1): 21-40. DOI: 10.1177/0093854808326545.

Cámara de Diputados (2008). Reforma Constitucional de Seguridad y Justicia. Gobierno Federal. Disponible en https://bit.ly/37i66Wa.

Carvajal, Jorge Enrique, Carlos Arturo Hernández y José Eduardo Rodríguez (2019). «La corrupción y la corrupción judicial: Aportes para el debate». Revista Prolegómenos, 22 (44): 67-82. Disponible en https://bit.ly/zeajaPU.

Chollet, Francois (2018). Deep Learning with Python. Nueva York: Manning Publications Co.

Comisión Ejecutiva de Atención a Víctimas (CEAV) (2015). Modelo integral de atención a víctimas. Disponible en https://bit.ly/3tuALIC.

Comisión Interamericana de Derechos Humanos (2019). Corrupción y derechos humanos: Estándares interamericanos. Disponible en https://bit.ly/3ghNivc

Corvalán, Juan (2018). «Inteligencia Artificial: retos, desafíos y oportunidades Prometea: La primera Inteligencia Artificial de Latinoamérica al servicio de la Justicia». Revista de Investigações Constitucionais, 5 (1): 295-316. Disponible en https://bit.ly/36sUQ9R.

Dieterich, William, Christina Mendoza y Tim Brennan (2016). «COMPAS Risk Scales: Demonstrating Accuracy Equity and Predictive Parity». Northpointe Inc, 7 (7.4): 1. Disponible en https://bit.ly/2S4HRCC.

Estévez, Elsa, Pablo Fillottrani y Sebastián Linares (2020). PROMETEA: Transformando la administración de justicia con herramientas de inteligencia artificial. Washington D. C.: Banco Interamericano de Desarrollo. Disponible en https:// bit.ly/36grqvm.

Ferrajoli, Luigi (1995). Derecho y Razón. Madrid: Trotta.

-. (2011). «Constitucionalismo principialista y constitucionalismo garantista». Doxa: Cuadernos de Filosofía del Derecho, 34: 15-53. Disponible en https://bit.ly/2SdwLv5.

FonseCA, Roberto (2016). «Prueba ilícita: Regla de exclusión y casos de admisibilidad». Reforma Judicial. Revista Mexicana de Justicia, 1 (25): 27-53. Disponible en https://bit.ly/3xogCcb.

GadAMER, Hans-Georg (2006). Estética y Hermenéutica. Madrid: Tecnos-Alianza

GonzÁlez, Graciano (2004). «El imperativo tecnológico: una alternativa desde el humanismo». Cuadernos de bioética, 15 (53): 37-58. Disponible en https://bit. ly/3vgGjHB.

GuibourG, Ricardo (2015). «Derecho, tecnología, inteligencia artificial y web semántica. Un mundo para todos y para cada uno». En Álvaro Núñez y Jorge Luis Fabra (coordinadores), Enciclopedia de Filosofía y Teoría del Derecho, volumen uno (pp.791-823). Ciudad de México: UNAM. Disponible en https://bit.ly/zah3JEw. 
Held, Klaus (2002). «Asombro, tiempo, idealización. Sobre el comienzo griego de la filosofía». Estudios de Filosofía, 26: 64-74. Disponible en https://bit.ly/2ZjZySl.

Јаковs, Günther (1995). Derecho penal: parte general. Fundamentos y teoría de la imputación. Madrid: Marcial Pons, Ediciones Jurídicas.

JAKoBs, Günther y Cancio Meliá, Manuel (2006). Derecho penal del enemigo. Madrid: Civitas.

Lefranc, Federico (2016). «Los sujetos de la SIC». En Evelyn Téllez (coordinadora), Derecho y TIC. Vertientes actuales (p. 33-47). Instituto de Investigaciones Jurídicas. Ciudad de México: UNAM. Disponible en https://bit.ly/3n93iR8.

LÉvinas, Emmanuel (2015). Ética e infinito. Madrid: Machado Libros.

Malem SeÑa, J. F., Javier Ezquiaga Ganuzas y Perfecto Andrés (2012). El error judicial. La formación de los jueces. Ciudad de México: Fontamara.

Medvedeva, Masha, Michel Vols y Martijn Wieling (2020). «Using machine learning to predict decisions of the European Court of Human Rights». Artificial Intelligence and Law, 28: 237-266. Disponible en https://bit.ly/36eG2vh.

MerCader, Jesús (2017). «El impacto de la robótica y el futuro del trabajo». Revista de la Facultad de Derecho de México, 67 (269): 149-174. Disponible en https://bit. ly/3jQIGMx.

Montano, Pedro (2016). «Incidencia de la víctima para la individualización de la pena». Instituto de Derecho Penal (Montevideo), 5: 1-13. Disponible en https://bit. ly/3gjPC4U.

Olivera, Noemí (2010). «Estado de la cuestión en la relación entre derecho e informática». Anales de la Facultad de Ciencias Jurídicas y Sociales, 7 (40): 507-517. Disponible en https://bit.ly/34bZTZU.

Parliamentary Assembly (2020). Artificial Intelligence: Ensuring respect for democracy, human rights and the rule of law. Disponible en https://bit.ly/3qhKaTd.

Pereira, Santiago (2016). «El principio de inmediación en el proceso por audiencias: mecanismos legales para garantizar su efectividad». Revista internauta de práctica jurídica, 11. Disponible en https://bit.ly/2Q463YE.

Posner, Richard (2011). Cómo deciden los jueces. Madrid: Marcial Pons.

Ríos, Carlos (2012). «El Proceso Acusatorio en el estado de Chihuahua y el caso del homicidio de Rubí Fraire». En D. Cienfuegos Salgado y G. Froto Mandariaga (editores), Los derechos humanos en el momento actual (pp. 403-416). Ciudad de México: UNAM. Disponible en https://bit.ly/3doVgky.

Roxin, Claus (1997). Derecho penal. Parte general, I. Fundamentos. La estructura de la teoría del delito. Madrid: Civitas.

RUA, Gonzalo y Leonel González (2017). «Las salidas alternativas al proceso penal en América Latina. Una visión sobre su regulación normativa y propuestas de cambio». CEJA-INECIPCEJA-INECIP: 99-124. Disponible en https://bit.ly/3hKTXyL. 
Sourdin, Tania (2018). «Judge v Robot? Artificial Intelligence and Judicial Decisionmaking». UNSW Law Journal, 41 (4): 1114-1133. Disponible en https://bit.ly/33bPSvR. SChirrmacher, Frank (2014). Ego: Las trampas del juego capitalista. Barcelona: Ariel. SuÁrEZ, José Leonardo (2011). «Inferencia razonable, probabilidad de verdad y conocimiento más allá de toda duda razonable». Principia Iuris, 16: 307-330 Disponible en https://bit.ly/3x7eLFn.

Supiot, Alain, (2007). Homo juridicus. Un ensayo sobre la función antropológica del derecho. Buenos Aires: Siglo XXI editores.

Suprema Corte de Justicia de la Nación (2020a). Protocolo para Juzgar con Perspectiva de Género. Disponible en https://bit.ly/37icj42.

Suprema Corte de Justicia de la Nación (2020b). Reforma con y para el Poder Judicial. Disponible en https://bit.ly/3dfRydl.

TAYro, Erwin (2016), «La videoconferencia. Un nuevo enfoque del principio de inmediación procesal». Revista Oficial Del Poder Judicial. Órgano De Investigación De La Corte Suprema De Justicia De La República Del Perú, 8(10), 547-559. DOI: 10.35292/ropj.v8110.251.

Tenorio, Fernando (2014). El delito y el control del delito en la modernidad avanzada. Saarbrücken: Publicia.

Tiqqun (2015) La hipótesis cibernética. Madrid: Machado Libros.

VILlanueva, Ernesto (2015). Derecho de las nuevas tecnologías (en el siglo XX derecho informático). Ciudad de México: Oxford University Press.

Zaffaroni, Eugenio Raúl (1998a) Criminología. Aproximación desde un margen. Bogotá: Temis.

-.(1998b). En busca de las penas perdidas. Deslegitimación y dogmática jurídico-penal. Buenos Aires: Ediar.

-. (2019). La nueva crítica criminológica. Criminología en tiempos de totalitarismo financiero. Buenos Aires: Ediar.

Zaffaroni, Eugenio Raúl, Alejandro Alagia y Alejandro Slokar (2006). Manual de Derecho Penal. Parte General. Argentina: Ediar.

ZAVALETA, Roger (2014). «Los problemas de justificación externa como problemas del caso». En Mayolo García y Rodolfo Moreno (coordinadores), Argumentación jurídica. Fisonomía desde una óptica forense (pp.127-150). Ciudad de México: UNAM. Disponible en https://bit.ly/3mWjRA9.

\section{Sobre la autora}

Juliana Vivar Vera es abogada, maestra en Derecho, maestra en Ciencias Penales y doctora en Derecho. Profesora en el Tecnológico de Monterrey, Escuela de Ciencias Sociales y Gobierno. Su correo electrónico es jvivarv@tec.mx. (D) https://orcid. org/oooo-0002-8759-9938. 


\title{
REVISTA CHILENA DE DERECHO Y TECNOLOGÍA
}

La Revista de Chilena de Derecho y Tecnología es una publicación académica semestral del Centro de Estudios en Derecho Informático de la Facultad de Derecho de la Universidad de Chile, que tiene por objeto difundir en la comunidad jurídica los elementos necesarios para analizar y comprender los alcances y efectos que el desarrollo tecnológico y cultural han producido en la sociedad, especialmente su impacto en la ciencia jurídica.

\author{
EDITOR GENERAL \\ Daniel Álvarez Valenzuela \\ (dalvarez@derecho.uchile.cl) \\ SITIO WEB \\ rchdt.uchile.cl \\ CORREO ELECTRÓNICO \\ rchdt@derecho.uchile.cl \\ LICENCIA DE ESTE ARTÍCULO \\ Creative Commons Atribución Compartir Igual 4.o Internacional
}

\begin{abstract}
La edición de textos, el diseño editorial
y la conversión a formatos electrónicos de este artículo

estuvieron a cargo de Tipográfica

(www.tipografica.io).
\end{abstract}

